\title{
WestVirginiaUniversity
}

THE RESEARCH REPOSITORY @ WVU

Graduate Theses, Dissertations, and Problem Reports

2019

\section{Acoustics of Vowel Articulation in Flute Playing}

Jose Fernando Ramirez

West Virginia University

Follow this and additional works at: https://researchrepository.wvu.edu/etd

\section{Recommended Citation}

Ramirez, Jose Fernando, "Acoustics of Vowel Articulation in Flute Playing" (2019). Graduate Theses, Dissertations, and Problem Reports. 3829.

https://researchrepository.wvu.edu/etd/3829

This Thesis is protected by copyright and/or related rights. It has been brought to you by the The Research Repository @ WVU with permission from the rights-holder(s). You are free to use this Thesis in any way that is permitted by the copyright and related rights legislation that applies to your use. For other uses you must obtain permission from the rights-holder(s) directly, unless additional rights are indicated by a Creative Commons license in the record and/ or on the work itself. This Thesis has been accepted for inclusion in WVU Graduate Theses, Dissertations, and Problem Reports collection by an authorized administrator of The Research Repository @ WVU. For more information, please contact researchrepository@mail.wvu.edu. 


\section{Acoustics of Vowel Articulation in Flute Playing}

Jose Fernando Ramirez

Jose Fernando Ramirez 


\title{
Jose Fernando Ramirez-Macias
}

\author{
Thesis submitted \\ to the Eberly College of Arts and Sciences \\ at West Virginia University \\ in partial fulfillment of the requirements for the degree of \\ Master of Arts in \\ Linguistics \\ Jonah Katz, Ph.D., Chair \\ Sergio Robles-Puente, Ph.D. \\ William Koehler, DMA. \\ Department of World Languages, Literatures and Linguistics
}

\author{
Morgantown, West Virginia \\ 2019
}

Keywords: Flute, vowels, acoustics, fundamental, overtones, tone, music, linguistics Copyright 2019

Jose Fernando Ramirez-Macias 


\section{ABSTRACT \\ Acoustics of vowel articulation in flute playing \\ Jose Fernando Ramirez-Macias}

Through an experiment and series of acoustic analysis, this thesis evaluates if vowel articulation modifies flute sound. It is an initial investigation in a sequence of research on linguistics solving major questions in flute performance and teaching, and is a continuation of a previous pilot project called "Acoustics and Perception of Speech Sound on the Flute," where participants attempt to distinguish vowel articulation of the mouth while playing the flute. In this thesis, the flute sound is tested acoustically to provide evidence of how vowels alter the timbre. To this end, a professional flutist recorded $\mathrm{A}=440 \mathrm{~Hz}$ in the three octaves of the flute. The participant played one pitch while shaping the mouth using one monophthong. The first recording used peripheral vowels on the IPA, while in a second recording the flutist played vowels contrasting in jaw height on the IPA, therefore producing a total of thirty samples. The collected data was evaluated using spectra analysis, overall loudness, and specific spectral prominences to explain in different dimensions how flute sound behaves in isolation.

The results did not show consistent evidence proving timbre differences. The changes in spectra are small, not related to vowel articulation and quality, giving random results within a specified range. The results provide evidence that the acoustics of phonetic vowels do not correspond to flute sound; rather, different phenomena govern them. 


\section{ACKNOWLEDGEMENTS}

Words are not able to express the gratitude I feel for all the supporting and loving people around me. I would like to honor their presence in my life by acknowledging their important role. They provided me with the tools and support to successfully finish my thesis. First, I want to thank Hugo, my dad, Nubia, my mom, and Juan Alberto, my brother. Their love and support are the core of who I am today. I would also like to thank all my family, especially my grandmother, whose qualities I strive to emulate in my life. Not only is she an essential part of the family that binds everyone together, but to me she is an example of how to live peacefully and wisely. Additionally, I want to thank the Correa Londoño family, especially my girlfriend Lina, who provided hours of companionship and patience. Her dedication has allowed me to view my work from a different perspective. She has also improved my work by increasing its coherence and helping me see different possibilities. Most importantly, she has given me courage even in the most difficult times.

I would like to thank Dr. Katz, the chair of my committee, for assisting and guiding me through my thesis from the very beginning. He has provided me with countless hours of tutoring and advice to shape my thesis into what it is today. Also, the feedback and ideas from the other members of the committee, Dr. Robles-Puente and Dr. Koehler, helped me improve my work and supported my passion for the connection between music and linguistics.

I would like to thank the WVU flute studio, especially Alyssa Schwartz for her participation in the experiment and her research. Because of her contribution, I was able to develop my research to the furthest extent possible. Additionally, thank you to Professor Nina 
Assimakopoulos, who intrigued me about the relationship between vowel articulations and flute sound.

Thank you to the Writing Studio for helping me refine my thoughts and increase the readability of my thesis as a whole; specifically, Alexandra Persad and Taylor Miller for their dedication and writing advice.

To the Language Department, specially my friends in the Spanish, German and French departments, thank you for supporting me during my master's.

Finally, I want to thank all the people that directly or indirectly helped me to be in this point of my life. I would like to acknowledge these individuals in addition to the previously mentioned for the impact they have had. 


\section{CONTENTS}

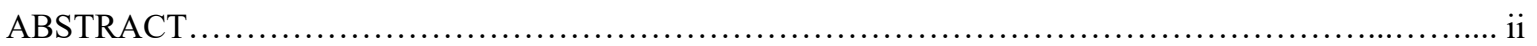

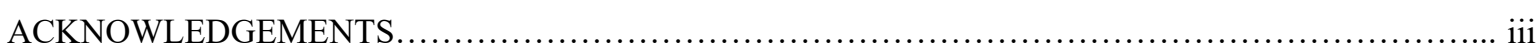

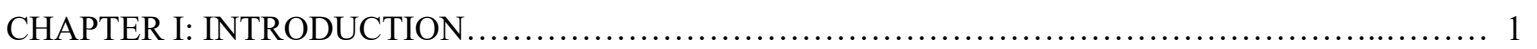

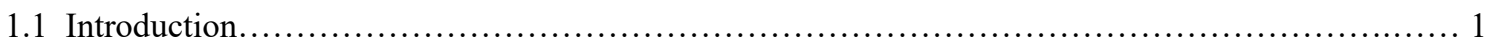

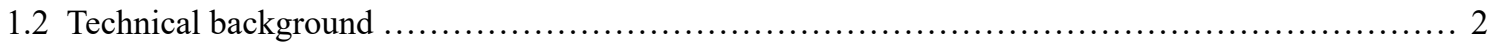

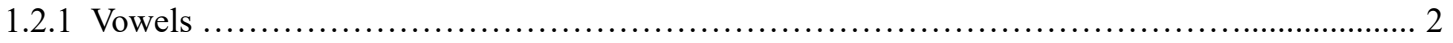

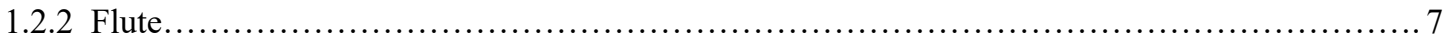

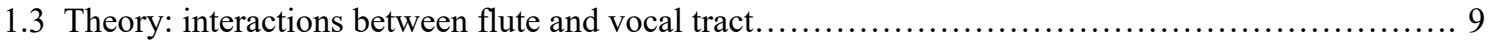

1.3.1 Previous research: scientific research and claims about flute sound and vowel articulations.......9

1.3.2 Linguistic claims - reasons to doubt the utility of vowel shapes in flute sound................... 11

1.3.2.1 Effects of vowel should depend on speaker, flute, and note........................... 11

1.3.2.2 Filtered aerodynamic output: lips and embouchure................................. 12

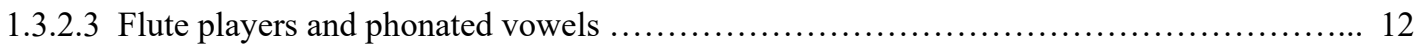

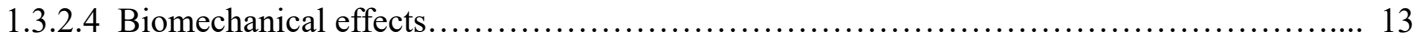

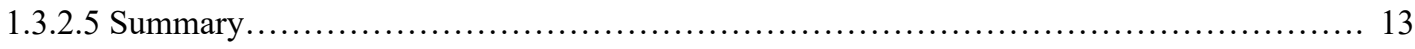

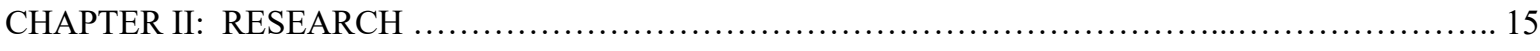

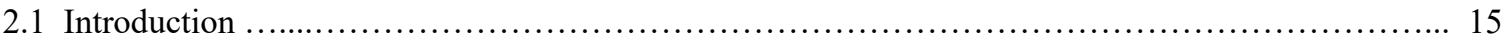

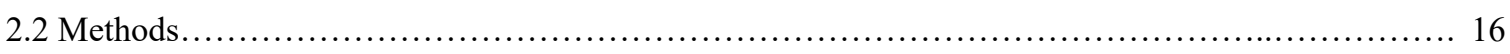

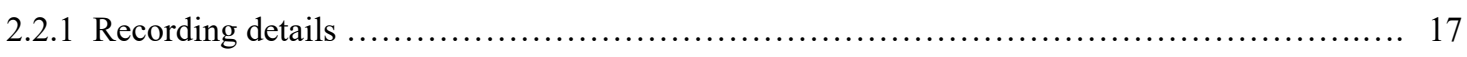

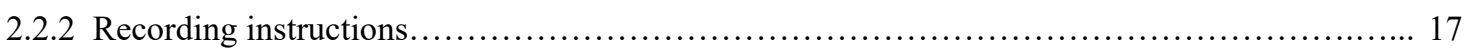

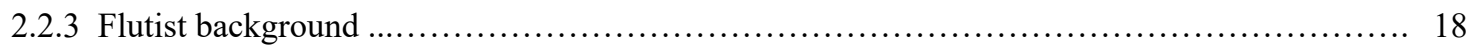

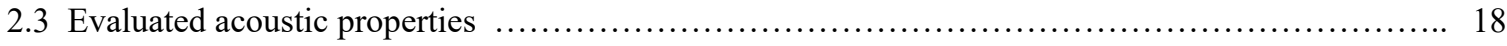

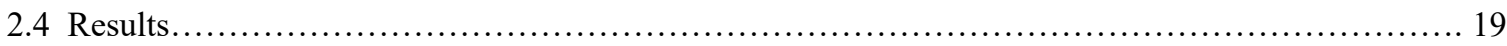

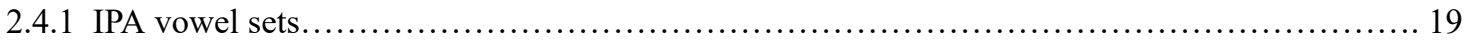

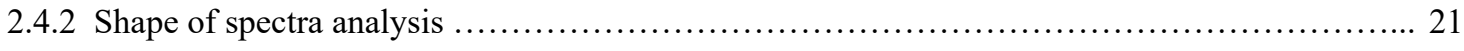

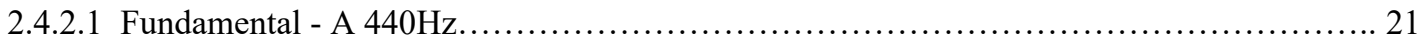

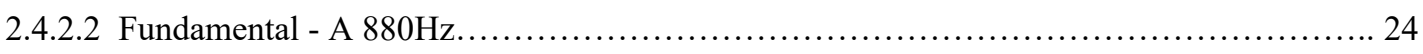

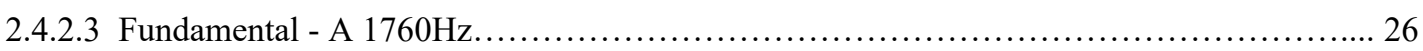

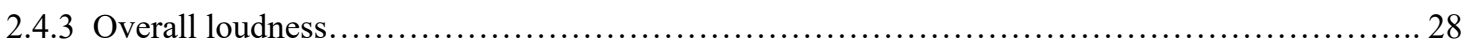

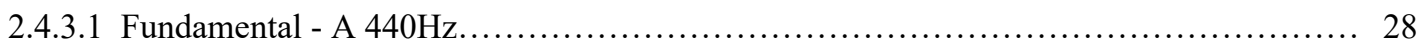

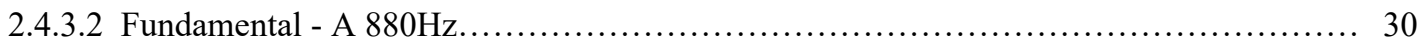

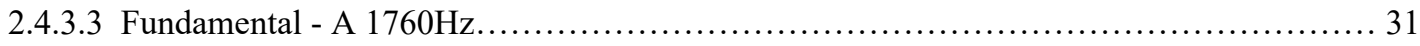

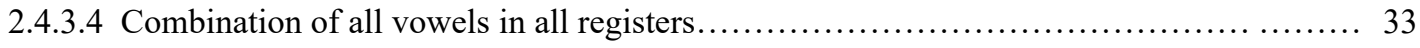

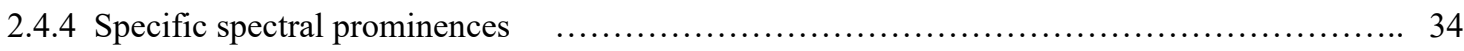




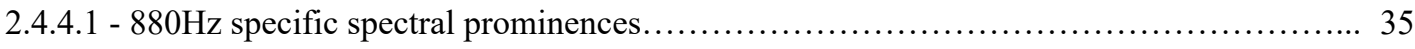

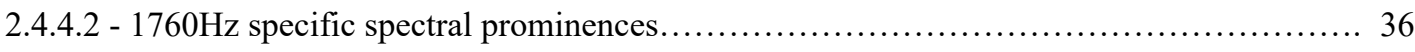

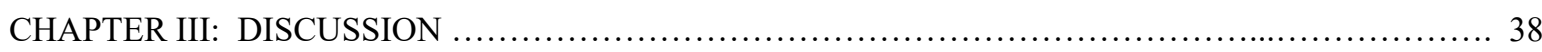

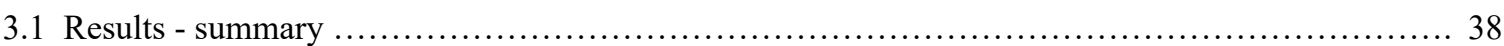

3.1.1 Measure correlation between series...................................................... 40

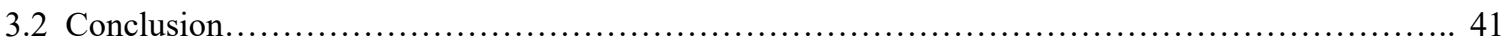

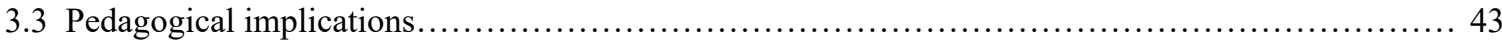

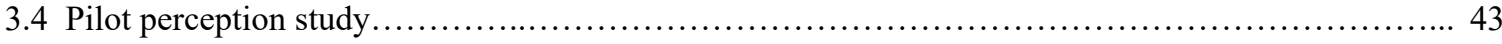

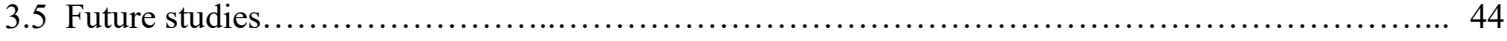

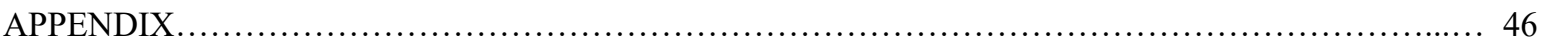

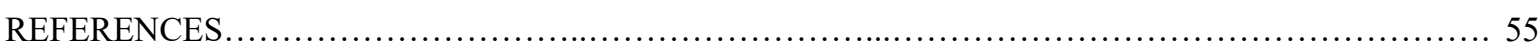




\section{CHAPTER I: INTRODUCTION}

\subsection{Introduction}

The beginning of this paper concerns itself with finding particular, pre-existing conventions as to how vowel articulations ${ }^{1}$ could affect the western traverse flute sounds. This research systematically highlights relevant information with a narrowed focus on a two-part hypotheses. This thesis will discuss more precisely how vowel articulation without voicing may affect sounds within the flute guided by the hypothesis that, if so, humans could have the ability to detect the articulated vowels in isolation and in a series. Nonetheless, this work itself does not discuss some aspects of flute technique such as vibrato, tonguing, dynamics, and simultaneous voice/flute sound instances. The reason for this is to isolate the proposed phenomena at hand with the goal of precisely assessing the acoustic and perceptual aspects of subsequent research.

Overall, physical/linguistic and flutist aspects are taken into account, noting on one hand that the oral cavity and the flute are in a sense two different instruments with which music can be influenced. Since there is no additional, inserted, or assistive device in the mouth, such as a reed, used to control the way sound is produced, there should not be any significant changes in aspects of timbre if the flutist generates changes within the oral cavity. This would appear to make vowel changes difficult for the listener to identify. In contrast, expert flutists utilize different vowel shapes, claiming that the resonance spectrum or monophthongs make it possible to blend the sound with other instruments and produce different resonance qualities in a instrument. In such

\footnotetext{
${ }^{1}$ Articulation for wind instruments is also referred to as tonguing. It is a technique that allows performers to use the tongue to separate and enunciate the beginning of the sound. In this work, word articulation takes its meaning from linguists, which refer to a broad range of change of the configuration of the vocal tract.
} 
an instance, the oral cavity modifies the energy produced by the lungs, hence suggesting that the quality of sound changes is wavering, and humans should be capable of detecting such variances or changes. The methodology of this work aims to solve through experiments how vowel shapes affect sounds in the flute and detect if humans can identify vowel changes in flute sound.

\subsection{Technical background:}

This section discusses the main concepts and elements of this work, which concerns vowel articulations from an acoustic point of view and flute sounds from an acoustic and physics perspective. Finally, it assesses if the combination of vowel shapes will affect flute sound.

\subsubsection{Vowels}

Vowels are used mainly in speech. Linguists have exhaustively studied this phenomenon in order to understand it in depth. The following is a summarized explanation of how humans produce vowels and how vowels are measured.

When speaking, humans produce vowels by allowing air to pass through the vocal folds (Johnson 2010), which consist of a two-part tissue that vibrates while air moves through the vocal tract. The shape of the vocal tract determines the resonant frequencies of the sound that comes out of the mouth. The vowel quality changes when the shape of the vocal tract changes; linguists have characterized these changes principally in three dimensions (high - low, front back, rounded and unrounded). The IPA (International Phonetic Alphabet) vowels are illustrated in Figure 1 chart of vowels. 


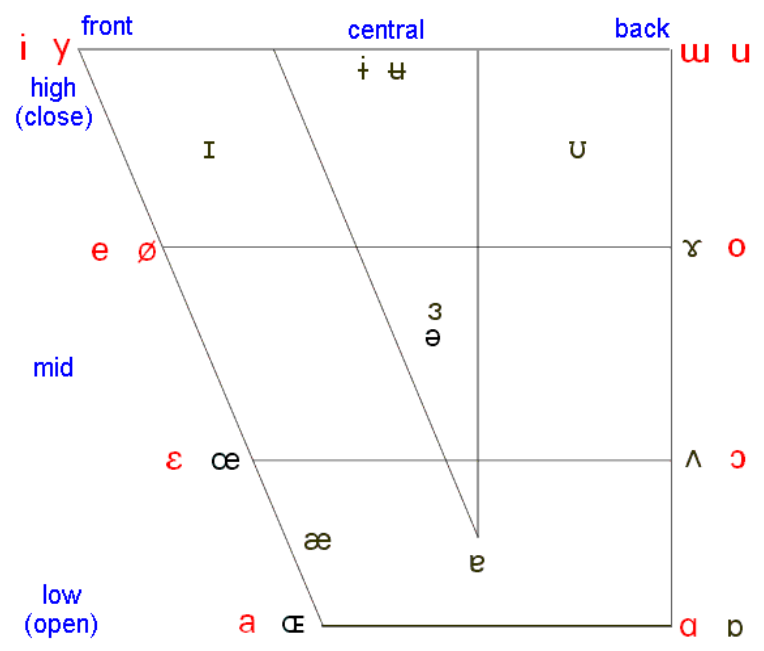

Figure 1. IPA (International Phonetic Alphabet). Vowel chart.

Vowels are measured using a spectrogram, which identifies the formants (the frequencies that determinate the phonetic quality of a vowel) and is the combination of two elements: the harmonic spectrum of sound from the vocal folds and the resonance of the vocal tract. Figure 2 shows the individual phenomena of resonance. First, it shows the resonances of the vocal tract, then the harmonic spectrum of the sound from the vocal folds, and finally, the bottom image is a combination of both. Figure 3 shows a representation of the vocal tract in vowels [a], [i], and [u]. Figure 3 also illustrates the resonance and harmonic spectra of the abovementioned vowels. The Y-axis measures loudness and the $\mathrm{X}$-axis measures Hertz $(\mathrm{Hz})$. The spectrograms assemble a variety of spectra at different time points to visualize how energy at various frequencies changes over time (see Figure 4). (Praat is a free computer software used to perform scientific analysis of speech in phonetics.) 


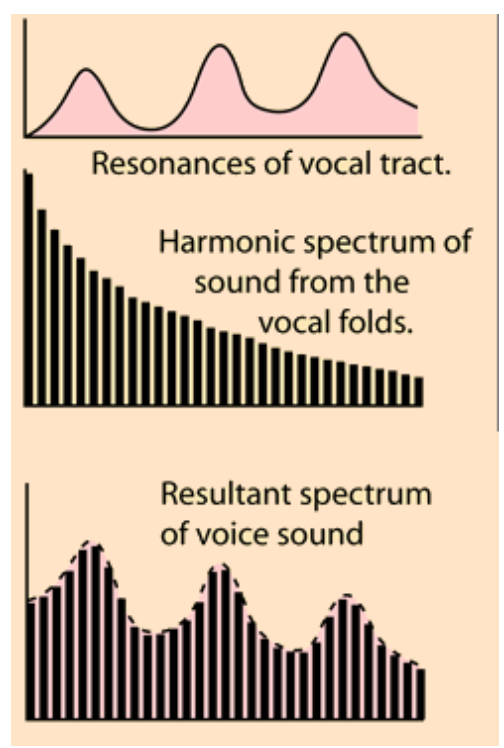

Figure 2. Resultant spectrum resonance and harmonic spectrum. http://hyperphysics.phy-astr.gsu.edu/hbase/Music/vocres.html
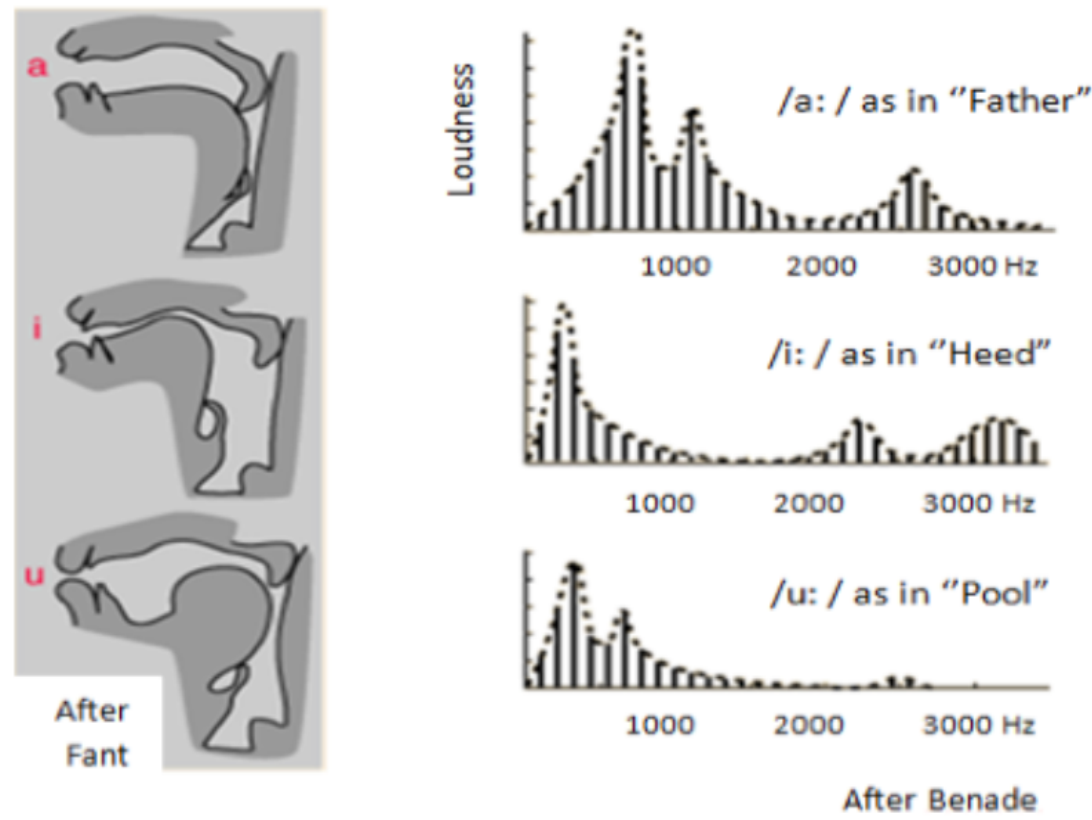

Figure 3. Schematic cross section of vocal tract of a male speaker for the three vowels [a:],[i:] and [u:] .Modified from http://hyperphysics.phy-astr.gsu.edu/hbase/music/vowel.html) . 
Figure 4 is a spectrogram of the vowels [i], [u], and [a] in the software "Praat." The red arrows show the values of formant 1 and formant 2. The Y-axis denotes Hertz values and the $\mathrm{X}$-axis represents time.

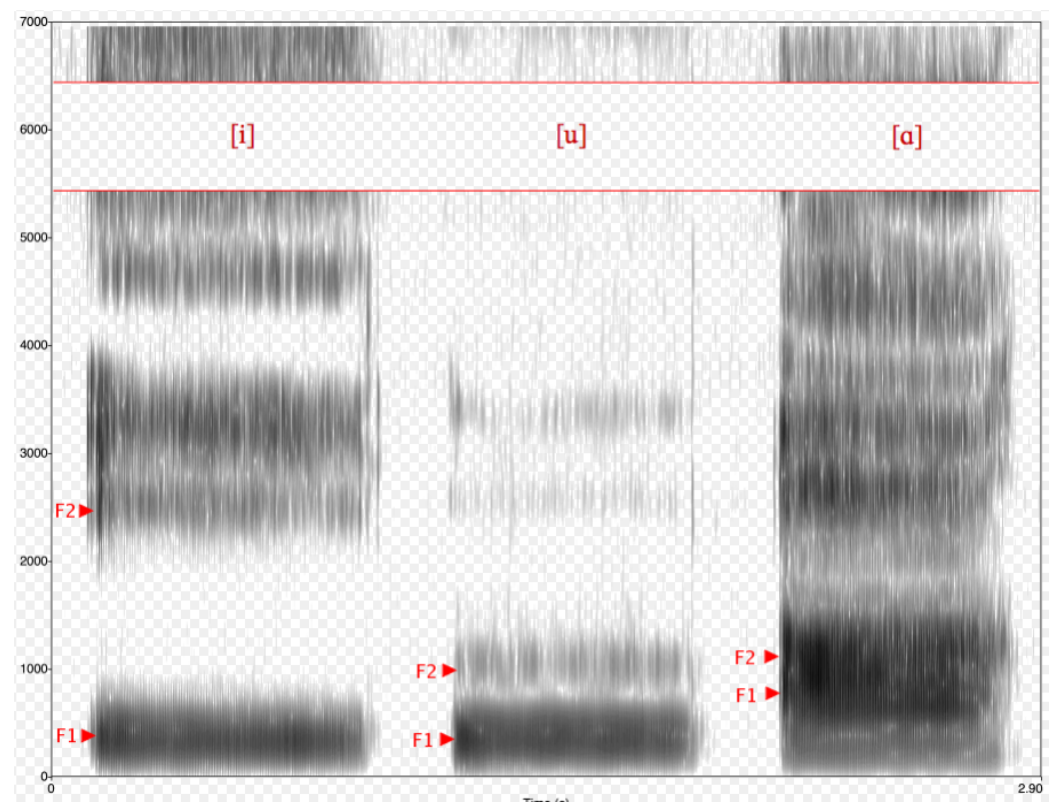

Figura 4. Formants in Praat of [i], [u], [a].

If vowels are measured in formant 1 and formant 2 , the values in Table 1 are expected. Nevertheless, those values are going to vary for different individuals depending on several factors, including gender and age. 


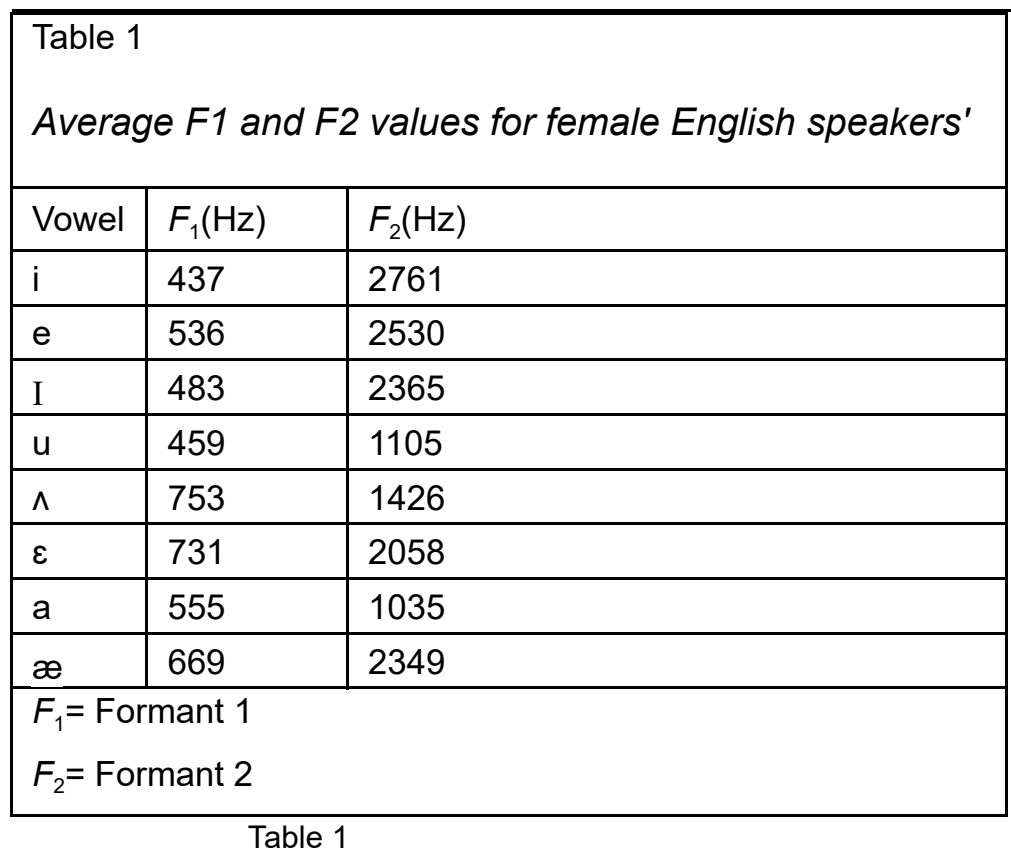

Although there is not an exact measurement for every person, the vowels could be represented in a plot similar to Figure 5. Setting formant 1 and formant 2 in the following figure will roughly recreate the image of the IPA plot shown in Figure 1. In order to achieve this graph, F2 requires the values to be more compacted than F1. Altering the configuration of F1 and F2 would give a different result. 
F2

$2500240023002200210020001900180017001600150014001300120011001000900 \quad 800 \quad 700 \quad 600 \quad 500$

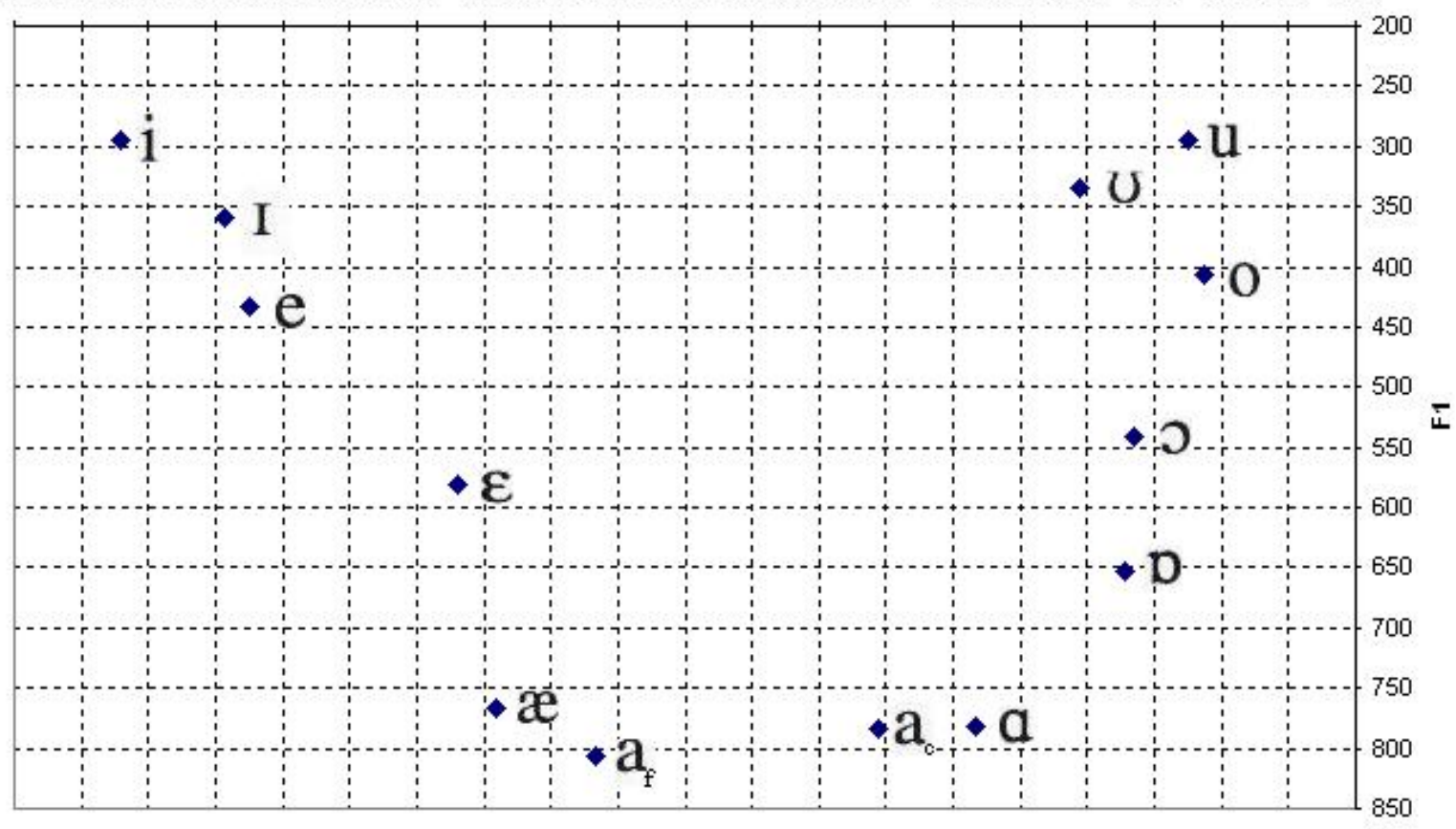

Figure 5. Representation of formant 1 and formant 2 in vowels.

\subsubsection{Flute}

The term flute in this thesis refers to the western traverse flute. In simple terms, a flute is a cylindrical instrument with holes. The embouchure is where the flutists place the mouth and where air goes in. Modern flutes are made out of metal, but it remains part of the woodwind family of orchestral instruments. In its evolution, the flute changed from wood to metal and added keys. As a whole, most flutes are made of nickel, silver, gold, or a combination of these metals. The system of keys developed by the musician and inventor Theobald Böhm (1794 1881), allows the instrument to go through the chromatic scale. 
To produce sound, the flutist produces a rapid air jet coming from the lungs. That air jet is energy that goes through the vocal apparatus and is condensed in the lips. The air goes out of the lips hitting the embouchure at a speed anywhere between 20 to 60 meters per second, depending on the pressure impressed by the flutist. When air hits the embouchure, the jet is divided in two; one part of the power goes inside the flute while the other flows outside. That phenomenon produces vibration that resonates in the instrument, thus projecting sound.

Figure 6 shows the breathing process: inhaling expands the chest and contracts the diaphragm, while exhaling contracts the chest and relaxes the diaphragm. Figure 7 illustrates how the lips direct air into the flute, then the air-power hits the embouchure, which divides the air in two - one part of the air goes inside and other outside of the instrument.

\section{Rebound Breath: Technique For Singers And Wind Players}

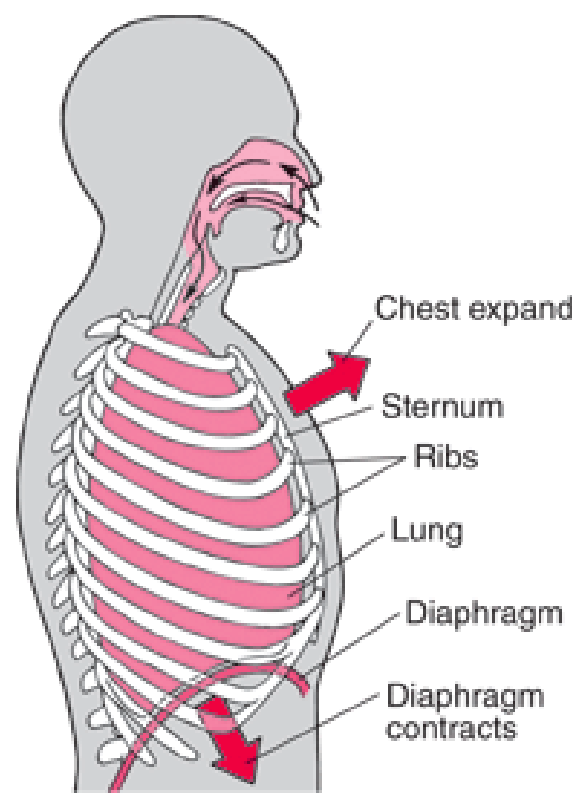

Inhalation

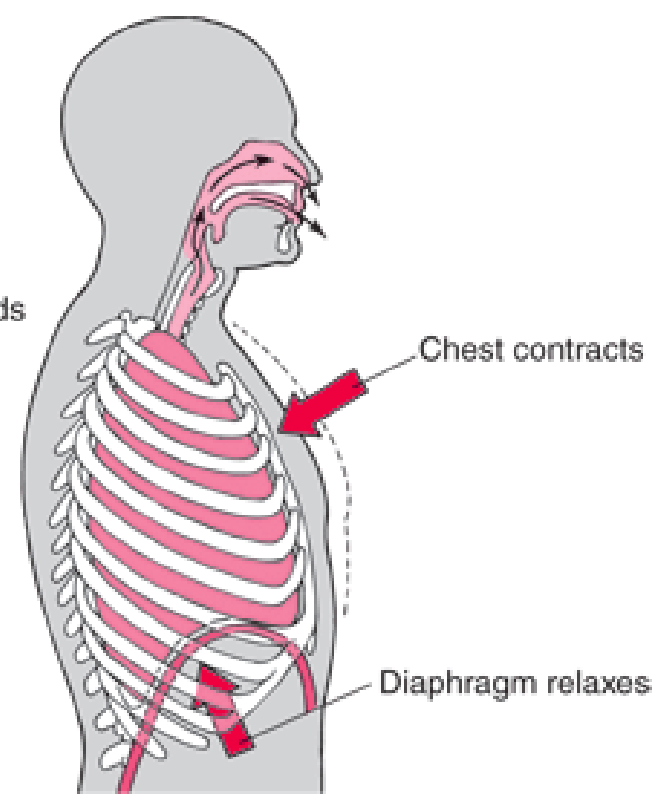

Exhalation

Figura 6. Rebound Breath: Technique for Singers and wind players. http://marlenehartzler.com/rebound-breath-technique-for-singers-and-wind-players/ 


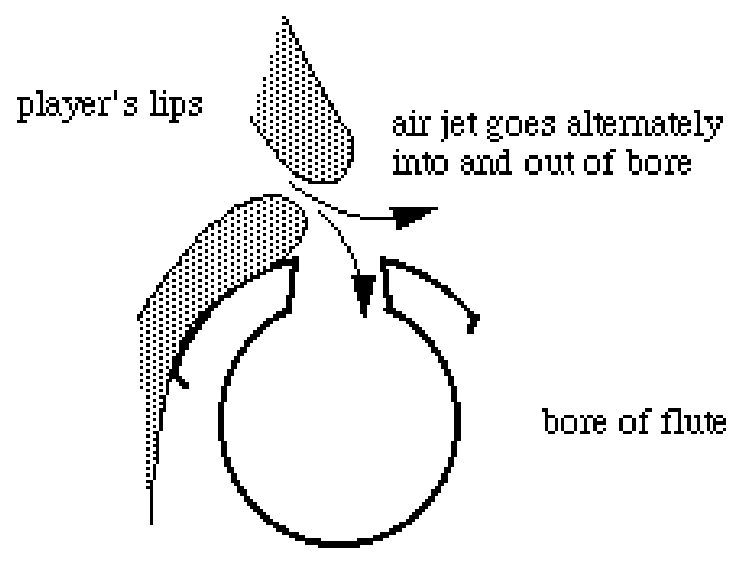

Figura 7. Flutist embochure https://newt.phys.unsw.edu.au/jw/fluteacoustics.html

\subsection{Theory: interactions between flute and vocal tract}

\subsubsection{Previous research: scientific research and claims about flute sound and vowel articulations}

Research papers (Gerda 2006, Schwartz 2018, Walker 1995, Walter 1978), internet pages (Miyasawa) and videos (Cela 2012) make claims supporting the theory that the vowel shapes inside the mouth directly affect the sound of the flute. Most of the arguments suggest that the chosen vowel manipulates the air going through the vocal tract, changing the vowel articulations, affecting the jet of air from the mouth, and altering the relative amplitude of harmonics in the flute. The effect in the spectral properties of the note is changed; the color (timbre) of the sound is different (Walker 1995) because some vowels seem to help produce a better tone than others in the flute (Walter 1978). Adding more color to music makes it more interesting, similar to painters using a wide variety of colors in their work (Gerda 2006); the colors in music are associated with 
the frequency in the spectra. Although there is no exact consensus, there is a general notion of relation between sound and qualities of matter. For instance, experts may say 'bright' and 'light' referring to sounds with more high-frequency energy in their spectra, and 'warm' and 'dark' refer to sounds with more low-frequency energy in their spectra. However, there are no exact measurements of when something is 'bright' or 'dark'. Additionally, "certain vowel positions yield a more or less homogenous blend with different instruments in their registers. When the placement of the first and second formants, the strength of the formants in relationship to the fundamental frequency and each other, and the overall spectral slopes more closely align between the sounds produced, a higher level of blend between the two instruments is achieved. When the formants or higher harmonics of one instrument are more present in the sound, the tone of that instrument tends to sound brighter by comparison. When the formants or higher harmonics of one instrument are less present in the sound, the tone tends to sound darker by comparison." (Schwartz 2018). The overtones are changed; therefore the color of the instrument changes. (Wincenc 1998:86).

The famous Irish flute virtuoso James Galway affirmed in 1982 that the tone of the flute is directly related to singing. He compares the techniques of the flute to singing techniques. Arguing that flutists should warm up as a singer does, a singer will use vowel sounds only, rather than words. He says that each vowel has a distinct sound, a different color, which the flute player can reproduce. The UK flutist Clarine Southworth also supports this idea, writing in 2010 for the internet page of Miyazawa, one of the most famous flute manufacturers in the world: "...vowels have the ability to add an open and warm quality and the articulation will create the drive and excitement" (Southworth 2010). 
According to Mayles (2017), by using back vowels such as [u] and [a], the flutist achieves 'bright' colors in sound. By using high vowels [i] and [u], the colors are 'darker'(Mayles 2017). The low vowels enhance louder and open sound, resulting in a warm tone. High vowels contribute to the articulation in the flute (the rapid stopping and starting of the airstream) by separating the stream of air blown in the flute because of their close proximity on the roof of the mouth (Clare 2010).

\subsubsection{Linguistic claims: reasons to doubt the utility of vowel shapes in flute sound}

\subsubsection{Effects of vowel should depend on speaker, flute, and note}

From an acoustic point of view, there are several reasons to doubt the theory proposed to the flutist. The information collected about vowels and acoustics does not match the assumptions of vowel shapes changing the timbre of the instrument. Nevertheless, in the case that the claim that vowel forms change the color of the flute is correct, there are many factors that should be considered. It is required to know at least the gender and the age of the flutist, as these factors change the spectrum values in vowels used in speech. People have different characteristics affecting vowel resonances due to varying vocal tract sizes and shapes. Also, the resonance spectrum of the flute and the pitch played affect the results. Different flutes have different spectra depending on the flute cavity shape. Other factors such as the thickness of the material, the material itself, the quality of the instrument, and the experience of the flutist also impact the overall results. All these variables change drastically in real life, thus the chances of different flutists reproducing the same results are unlikely. 


\subsubsection{Filtered aerodynamic output: lips and embouchure}

From an acoustic perspective, there are reasons to be skeptical about the flutists' claims of vowel articulations changing the timbre of the instrument. The lips in these phenomena work as a baffle. Imagining that some of the properties of the vowel could be transferred through the jet stream, those vowels would be filtered through the narrowed lips of the player. Even if a part of the information survives that filter, the aerodynamic output will hit the embouchure-hole and transfer the remaining property to the body of the flute. That resonance would destroy any vestige of vowel property. It is important to highlight that the flute has its own resonant frequencies that cannot be changed by the mouth. Changing the instrument shape will result in manipulation in timbre. The vowels in speech change because the resonance occurs in the mouth and, due to this cavity's ability to resonate sound, vowels are produced.

\subsubsection{Flute players and phonated vowels}

From a linguistic phonetic perspective, the claim of vowel shapes modifying flute sound lacks substantial argument. In traditional flute playing, the flutist does not produce phonated vowels. That is to say, the process of voicing never starts; the vocal folds do not move and, ideally, nothing interferes with allowing the jet stream to go into the flute. As a result, the flute produces a noisy jet-stream in which overtones are already set and give the characteristic sound of the instrument. Those are two distinct phenomena which work differently. It is possible to produce phonated vowels while playing the flute; however, its results and implications do not concern this work. 


\subsubsection{Biomechanical effects}

The above-stated reasons support a skeptical position from an acoustic point of view. However, even if there are no effects on the flute's spectrum (timbre), there are biomechanical effects that could interfere or allow loudness, which means that there should be parts of the body that could alternate the intensity (volume) of the sound.

Humans move parts in the vocal tract while speaking, including parts in the larynx, mouth, etc. Flutists do the same while playing. However, the position of the jaw or lips could change the angle or velocity of the jet stream hitting the embouchure-hole. Additionally, interference in the vocal tract would decrease the speed of air. Both position and angle affect energy transfer from the lungs to the flute.

The biomechanics should not affect the relative energy of different fundamental and overtones, the overtones are going to remain in their positions of the flute, but it could change overall loudness (volume).

\subsubsection{Summary}

Overall, vowels have negligible effect on flute acoustics because of external factors that impede the transfer of vowel quality to the flute, such as speaker, flute, and note, which all change drastically between each person. The sound is filtered through the lips and embouchure, which would destroy any transfer of the vowel quality. There are two different physical phenomena that apply to flute playing and phonated vowels which operate separately to produce sound. Even 
considering scepticism regarding the previously stated factors, the biomechanical effects of the flutist could affect the flute sound in volume in ways that the others factors do not. Expert implementation would be required in order to take these external factors into account. Even then, it is nearly impossible to predict a single note when measuring these factors. 


\section{CHAPTER II: RESEARCH}

There are pieces of evidence from two perspectives. One supports a theory where the vowel shapes manipulate flute spectrum (timbre, color) while the other is skeptical of manipulation. A test was designed to prove the potential consequences of vowels shapes. If there is any change, there must be scientific evidence that shows those differences and suggests an answer that denies or supports a side of the previous claims. Moreover, the results must show changes in the spectrum or gross intensity of the flute sound.

\subsection{Introduction}

In order to perform this experiment, an experienced flutist who had a thorough of knowledge of the theory of vowel articulations was recorded. This flutist not only incorporates this theory into her own performance but also her research. This affords the best likelihood to listen and compare the effects of this test. The recording contained samples of the player using different vowel shapes. The vowels contrasted drastically with each other to show a large amount of variation. In this experiment, a series of cardinal points in the IPA chart were recorded, followed by a set of front vowels. The recording had two pairs of samples of [i] and [e] to check for consistency. $[\mathrm{u}]$ is the only rounded vowel in the set; therefore, if there is any difference in rounding, this vowel articulation might show it. All samples were evaluated to see the spectrum and overall intensity of the flute sound. The software "Praat" is typically used to analyze speech, however, it was modified to analyze flute sound for the purpose of this experiment. A Praat script was configured to detect flute sound instead of human voice. It measured energy in the 
fundamental, first and second overtones, total intensity (volume), energy at the onset and the end of the note. Through this analysis, it is possible to identify the effect in vowel shape on the spectrum or gross intensity of flute sounds. Once the data is collected and organized, graphs can be designed in a spreadsheet to compare the given information visually.

This thesis is an exploratory study. A follow-up experiment with more data will be considered if there are remarkable patterns in the results. Although this study provides a limited data set as a first attempt, it provides enough information to make assumptions and generalizations about the topic and determine if it is worthwhile for students and researchers to continue inquiring.

\subsection{Methods}

This section explains the procedures carried out for this experiment, including the order of recording material and details about the setup, performance, and flutist.

Thirty samples from three tones were taken into account. The recorded tones were: A4= $440 \mathrm{~Hz}, \mathrm{~A} 5=880 \mathrm{~Hz}$ and $\mathrm{A} 6=1760 \mathrm{~Hz}$. The performer played each pitch shaping the oral cavity while playing in the following pattern: 1) [i] as in "need" (High - front - unrounded vowel), 2) [e] as in "wait" (high-mid front unrounded vowel), 3) [u] as in "boot" (High - back - rounded vowel), 4) $[\Lambda]$ as in "fun" (low-mid - back - unrounded vowel), and 5) [a] as in "car" (Low back - unrounded vowel).

To carefully investigate the impact of higher and lower vowels and analyze consistency, the flutist was recorded a second time playing the same notes. However, the performer followed a 
different order: 1) [i] as in "need" (High - front - unrounded vowel, the tongue body is advanced forward and the corona approximates the hard palate), 2) [I] as in "bit" (near-high - front unrounded vowel) 3) [e] as in "wait" (high-mid - front - unrounded vowel), 4) [E] as in "bed" (low-mid - front - unrounded vowel), and 5) [æ] as in "cat" (near-low - front - unrounded vowel). This order evaluates front vowels according to height, which contrasts with the previous cardinal vowels recording. Therefore, comparisons between the sound in various vowel dimensions, such as high-low, front/unrounded-back/rounded, can be drawn.

\subsubsection{Recording details}

The recordings have minimal external sound and no vibrato. The recording environment was a non-sound proof, but reasonably quiet, room. A head-mounted microphone was used to record and the flute was a gold Muramatsu. The flutist pronounced the vowel or a word where the vowel is included a few times before playing to ensure the shape of the mouth maintained the position of the isolated vowel while playing. However, the flutist did not produce sound in the vocal folds while playing.

\subsubsection{Recording instructions}

While playing $\mathrm{A} 4(440 \mathrm{~Hz})$, shape the mouth as one vowel, hold the note for four seconds. Follow this order to record in the first recording $[i],[\mathrm{e}],[\mathrm{u}],[\wedge]$ and $[\mathrm{a}]$. Leave silence space between each vowel. In a second recording follow this pattern $[\mathrm{i}],[\mathrm{I}],[\mathrm{e}],[\mathrm{E}]$ and $[æ]$. Repeat the same process for $\mathrm{A} 5(880 \mathrm{~Hz})$ and $\mathrm{A} 6(1760 \mathrm{~Hz})$. 
Recording \#1: [i], [e], [u], [^] and [a].

Recording \#2: [i], [I], [e], [E] and [æ].

\subsubsection{Flutist background}

The flutist recorded in this thesis is a talented and successful. The performer has won several competitions and prizes during her career, was part of the Flute Studio at West Virginia University, and finished her master and doctoral degrees at the same institution.

\subsection{Evaluated acoustic properties}

The first part of the evaluation concerns the spectral properties of each recorded pitch and vowel. In phonetic vowels, the intensity of each overtone indicates the changes (principally in values of formant 1 and formant 2). In this study, the fundamental, overtone 1 , and overtone 2 are evaluated in A $440 \mathrm{~Hz}, \mathrm{~A} 880 \mathrm{~Hz}$, and A $1760 \mathrm{~Hz}$. The intensity in different fundamental and overtones would indicate the change of the used vowel.

The second part of the evaluation concerns overall loudness in each pitch, The note is isolated and compared in vowel height in front vowels in IPA chart, Figure 8. The goal is to have overall loudness in each vowel and tone, and the final result is obtained by adding the values of the fundamental and the first and second overtones of the note. Additionally, the difference in loudness is measured by comparing the fundamental and overtones; fundamental - overtone 1 and overtone 1 - overtone 2. Finally, the energy on the onset and end of the note is determined. 
The third part of the test uses A $880 \mathrm{~Hz}$ as a fundamental compared with the first overtone of A $440 \mathrm{~Hz}$, which is also A $880 \mathrm{~Hz}$. The measurement in phonetic vowels notoriously changes. Therefore, it could show a high contrast in the flute, as in speech vowels. The same procedure is made using A $1760 \mathrm{~Hz}$ as a fundamental, it is compared with the first overtone of A $880 \mathrm{~Hz}$, which is also A $1760 \mathrm{~Hz}$. That measurement is taken at the beginning of the note.

\subsection{Results}

This section discusses in detail the sample recording procedures of the experiment. The first process consists of organizing the data in IPA vowel plots. This method of organization allows for evaluation of every pitch and vowel from two perspectives, a shape of spectra analysis, and overall loudness. Finally, the specific spectral prominences explanation concludes the previous findings. The terms mentioned above are clarified and expanded in each section of the chapter.

\subsubsection{IPA vowel sets}

Figures 8 to 10 are IPA (International Phonetic Alphabet) charts. They separate the recording into different categories. Figure 8 shows all vowels played by the flutist in the experiment. Figure 9 illustrates the cardinal points taken in the first recording; Figure 10 shows all front vowels taken in the second recording. Each phoneme has a number that is measured on a scale that was designed for this experiment. This number shows the height of the vowel, one being the lowest and five the highest; the measurement is used in overall loudness and spectral 
prominence. Vowels [i] and [e] meet the criteria of cardinal and front vowels. This repetition checks consistency in the results.

VOWELS

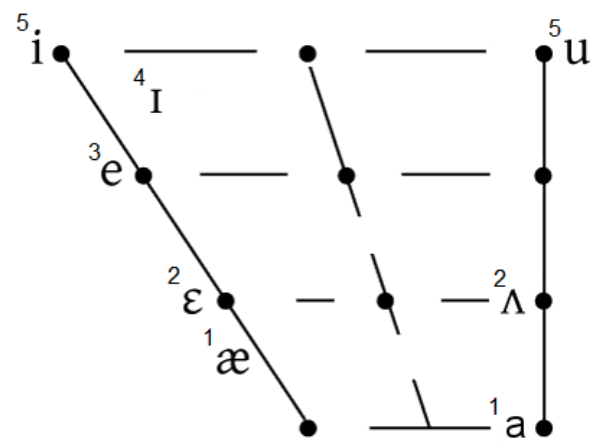

Figure 8. IPA Chart. Set of all vowels recorded

VOWELS

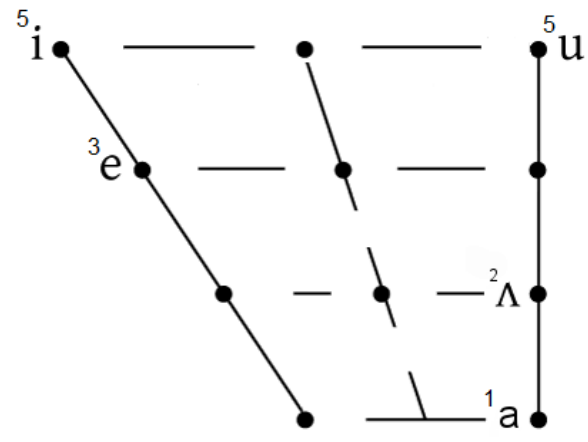

Figure 9. IPA Chart.Set of cardinal points. Recording \# 1

VOWELS

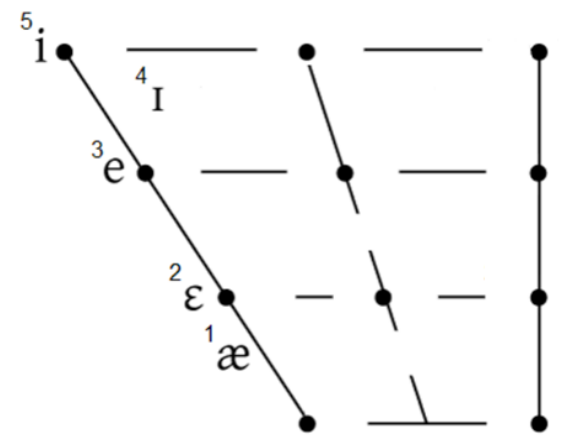

Figure 10. IPA Chart. Set of front vowels. Recording \#2 


\subsubsection{Shape of spectra analysis}

This section organizes all results and displays them in their spectral property for each pitch. The spectrum of the note is explained first using cardinal vowels, followed by front vowels. Although the real recordings do not always indicate an exact value of Hertz, they are in the same category. Therefore, the results are accurate. For each note, the chart on the left side shows the labels and values used in the graphs on the right side.

Each chart has five columns. The first column specifies the octave of the flute; the second column shows the used vowels, followed by the solfège syllables, and the Hertz. The next three columns present the energy (decibels) in the evaluated frequencies: the fundamental, first overtone and, second overtone, which in the script were realized as a1db, a2db and, a3db. To make it more intelligible, both labels are above the values. Additionally, some of the decimals in the results were deleted for practical purposes.

\subsubsection{Fundamental - A440Hz}

The first note to analyze is A $440 \mathrm{~Hz}$ (first octave of the flute) - the explanation evaluates its spectral properties from two perspectives: cardinal vowels and front vowels.

Graph 1 is a representation of the values shown in Table 2. It displays the decibel in A $440 \mathrm{~Hz}$ using cardinal vowel in the fundamental and its overtones. Graph 1 shows that all vowels have the same shape in backness and in height except one, [i]. If there were a correlation with a phonetic vowel, the line shapes should look different in their overtones, not solely upper unlike the others, with a remarkably similar shape. The pairs of [e] have the same form and are covering 
most of the possible spectrum of the other vowels; it suggests the same shape but in different locations. The [i] with different measures must be a lapse, the same pairs of [e] and the rest of the vowels have the same value.

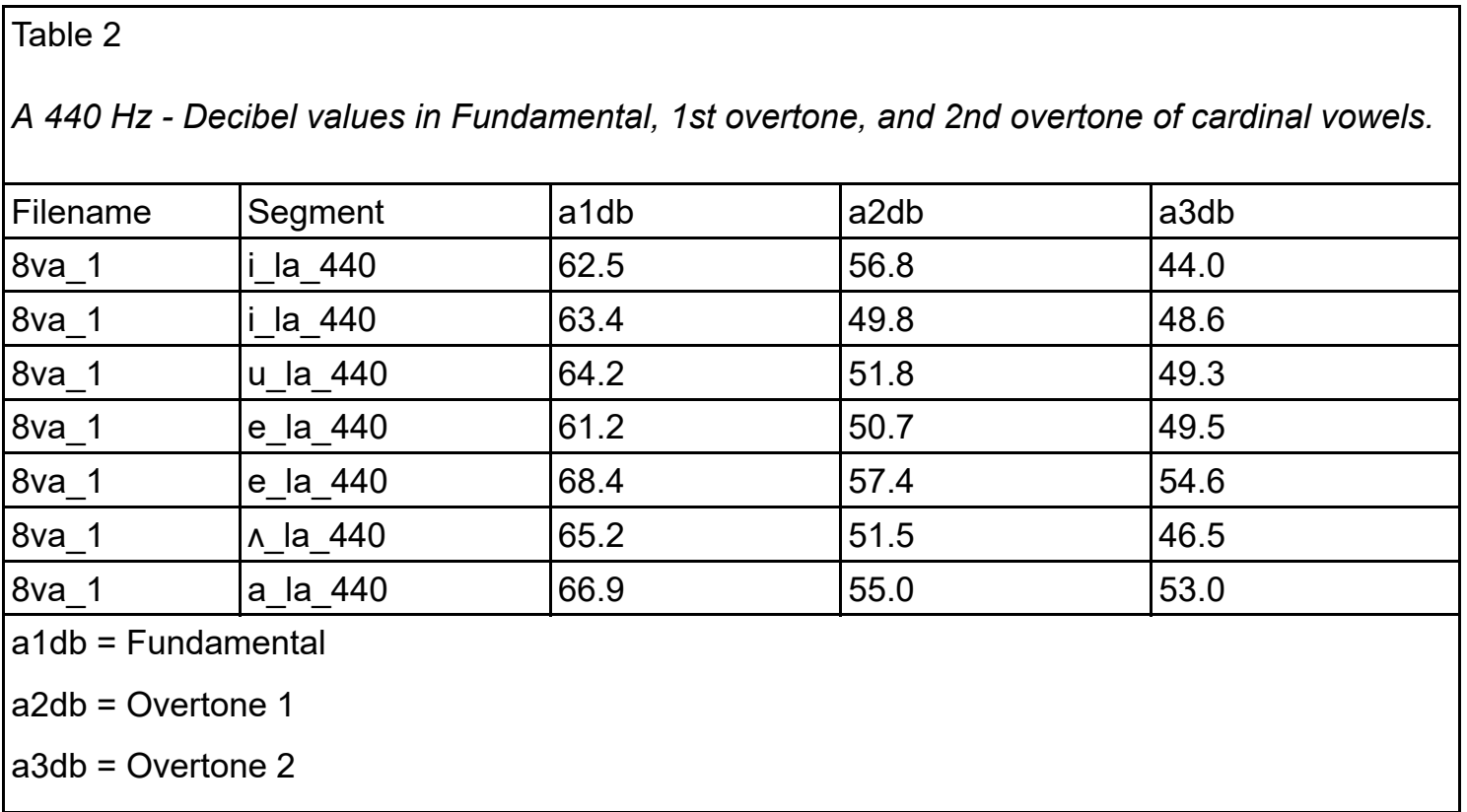

Table 2

\section{Cardinal vowels - $440 \mathrm{hz}$}

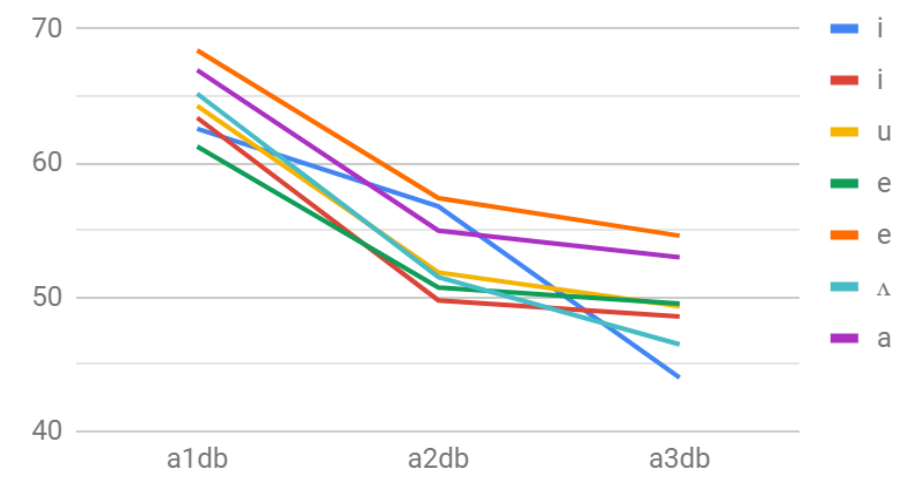

Graph 1. Cardinal vowels- $440 \mathrm{~Hz}$. Values in decibels of fundamental, 1 st overtone and 2nd overtone 
In Table 3, there is similar information that was shown in Graph 2. All vowels have the same shape except one [i]. There is no real contrast. The high front vowel [e] and the lowest front vowel [æ] are together with a similar form. As mentioned above, the two tokens of [e] are covering most of the possible spectrum of the other vowels.

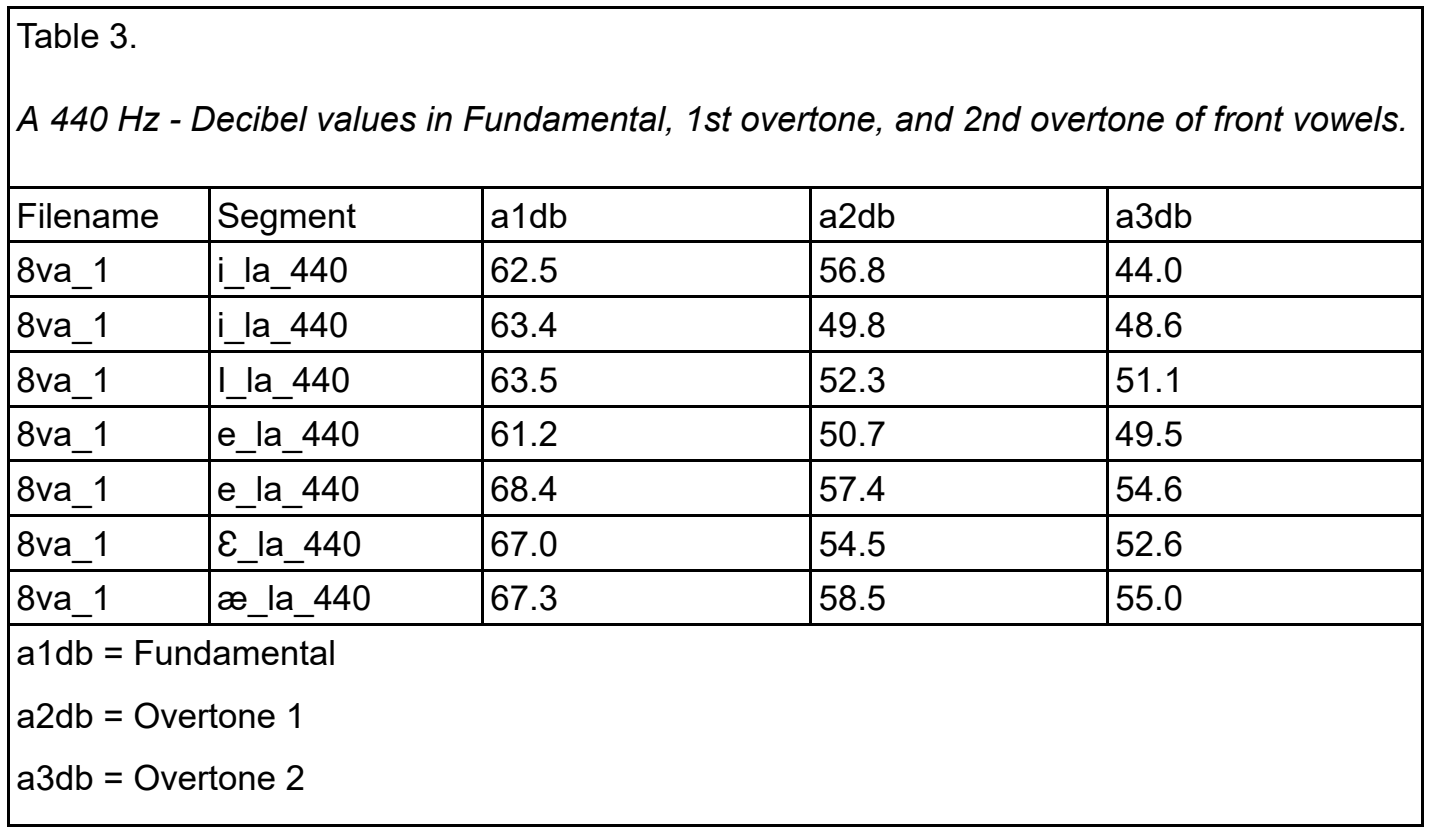

Table 3

\section{Front vowels - $440 \mathrm{~Hz}$}

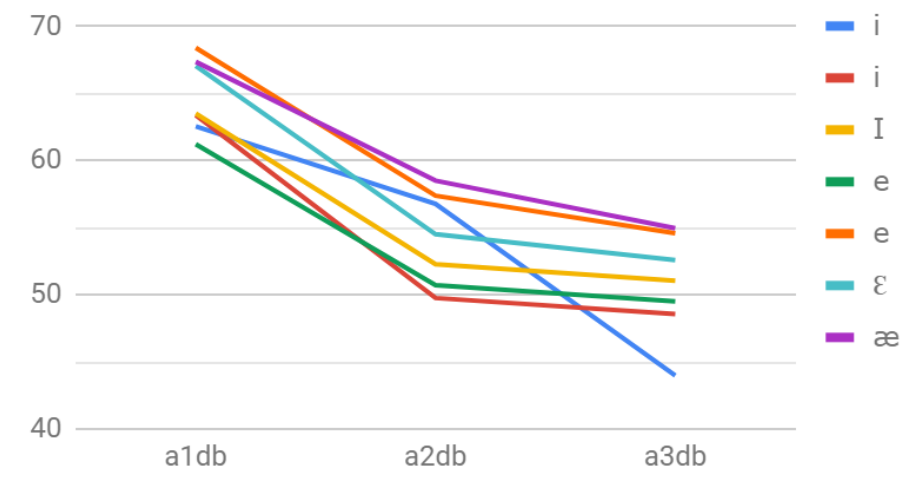

Graph 2. Front vowels - 440Hz. Values in decibels of fundamental, 1st overtone and 2nd overtone. 


\subsubsection{Fundamental - A $880 \mathrm{~Hz}$}

The second pitch to analyze is A $880 \mathrm{~Hz}$ (second octave of the flute). Graph 3 uses the information on Table 4 - A 880Hz; Graph 4 take values of Table 5 - A 880Hz. The two tokens of [i] cover almost the whole possible spectrum of the other results, which eliminates any possible correlation between a front/back and high/low vowel. Graph 4 shows the same results. In conclusion, there is no remarkable contrast, including cardinal vowels and front of vowels.

\begin{tabular}{|c|c|c|c|c|}
\hline $\begin{array}{l}\text { Table } 4 \\
\text { A } 880 ~ H z\end{array}$ & ecibel valu & lamenta & e, ano & of cardinal vowels. \\
\hline Filename & Segment & $a 1 d b$ & $a 2 d b$ & $a 3 d b$ \\
\hline 8va_2 & i_la_880 & 70.6 & 51.8 & 46.8 \\
\hline 8va_2 & i_la_880 & 67.4 & 39.6 & 39.0 \\
\hline 8va_2 & u_la_880 & 69.2 & 47.6 & 37.6 \\
\hline 8va_2 & e_la_880 & 68.7 & 45.4 & 37.3 \\
\hline 8va_2 & e_la_880 & 67.6 & 42.7 & 38.7 \\
\hline 8va_2 & ^_la_880 & 68.0 & 49.4 & 41.3 \\
\hline 8va_2 & a_la_880 & 68.5 & 49.2 & 41.9 \\
\hline $\mathrm{a} 1 \mathrm{db}=\mathrm{Fu}$ & amental & & & \\
\hline $\mathrm{a} 2 \mathrm{db}=\mathrm{O}$ & tone 1 & & & \\
\hline $\mathrm{a} 3 \mathrm{db}=\mathrm{O}$ & tone 2 & & & \\
\hline
\end{tabular}

Table 4

\section{Cardinal vowels - $880 \mathrm{~Hz}$}

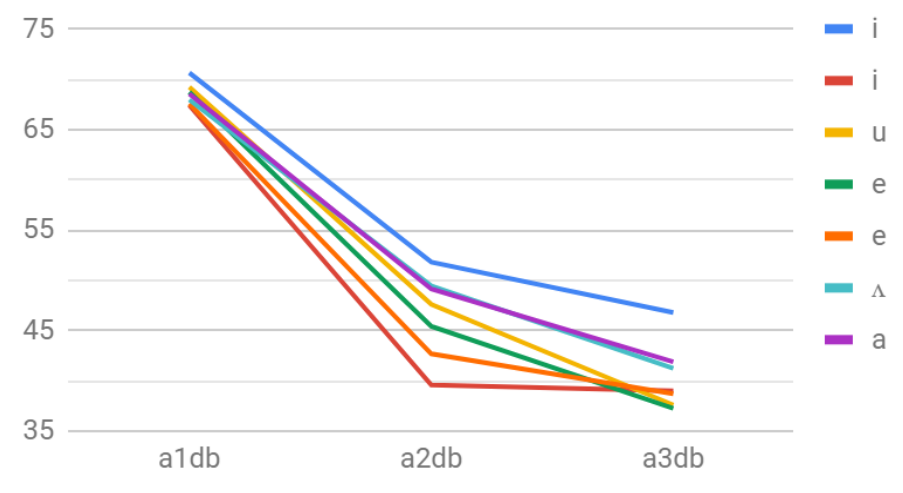

Graph 3. Cardinal vowels $-880 \mathrm{~Hz}$. Values in decibels of fundamental, 1 st overtone and 2nd overtone. 


\begin{tabular}{|c|c|c|c|c|}
\hline $\begin{array}{l}\text { Table } 5 \\
\text { A } 880 \mathrm{~Hz}\end{array}$ & Decibel val & undan & 'ertone, & rtone of front vowels. \\
\hline Filename & Segment & $a 1 d b$ & $a 2 d b$ & $a 3 d b$ \\
\hline 8va_2 & i_la_880 & 70.6 & 51.8 & 46.8 \\
\hline 8va_2 & i_la_880 & 67.4 & 39.6 & 39.0 \\
\hline 8va_2 & I_la_880 & 70.9 & 4.0 & 44.4 \\
\hline 8va_2 & e_la_880 & 68.7 & 45.4 & 37.3 \\
\hline 8va_2 & e_la_880 & 67.6 & 42.7 & 38.7 \\
\hline 8va_2 & E_la_880 & 69.7 & 47.5 & 44.5 \\
\hline 8va_2 & æ_la_880 & 69.4 & 44.2 & 41.6 \\
\hline $\mathrm{a} 1 \mathrm{db}=\mathrm{F}$ & ndamental & & & \\
\hline$a 2 d b=0$ & ertone 1 & & & \\
\hline$a 3 d b=0$ & ertone 2 & & & \\
\hline
\end{tabular}

Table 5

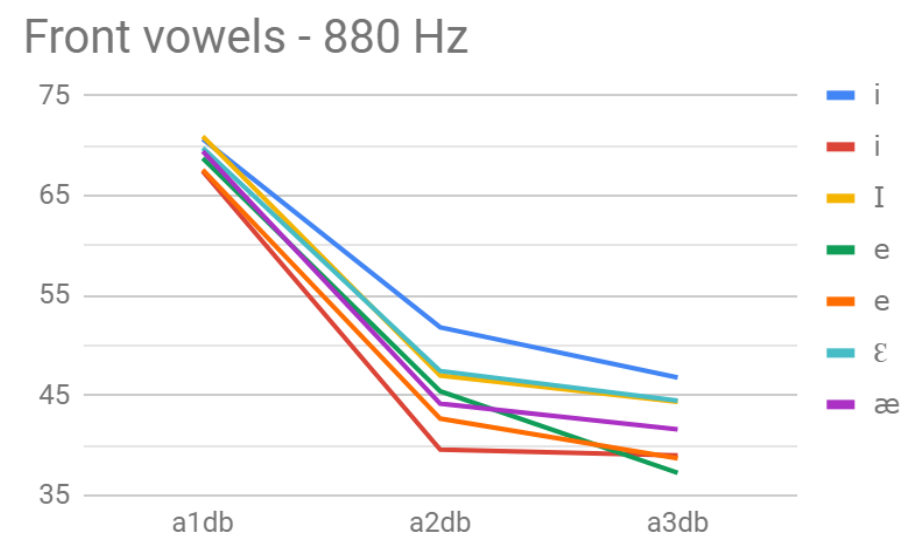

Graph 4. Front vowels $-8800 \mathrm{~Hz}$. Values in decibels of fundamental, 1st overtone and 2nd overtone. 


\subsubsection{Fundamental - A $1760 \mathrm{~Hz}$}

The third note to analyze is A $1760 \mathrm{~Hz}$ (third octave of the flute). As in the previous two pitches, there is a similar shape in overtones. The two tokens of [e] cover any possible difference between another vowel. One token of [i] is slightly different, having a decline in the second overtone. However, that difference is not relevant. There is no significant contrast between cardinal vowels (Table 6 and Graph 5) and front vowels (Table 7 and Graph 6).

\begin{tabular}{|c|c|c|c|c|}
\hline $\begin{array}{l}\text { Table } 6 \\
\text { A } 1760 \mathrm{H}\end{array}$ & - Decibel ve & damer & ne, an & e of cardinal vowels. \\
\hline Filename & Segment & $a 1 d b$ & $a 2 d b$ & a3db \\
\hline 8va_3 & i_la_1760 & 63.9 & 33.9 & 39.9 \\
\hline 8va_3 & i_la_1760 & 57.5 & 38.4 & 34.9 \\
\hline 8va_3 & u_la_1760 & 58.9 & 39.3 & 28.0 \\
\hline 8va_3 & e_la_1760 & 62.3 & 43.8 & 33.9 \\
\hline 8va_3 & e_la_1760 & 52.0 & 31.0 & 27.4 \\
\hline 8va_3 & ^_la_1760 & 55.6 & 36.8 & 30.1 \\
\hline 8va_3 & a_la_1760 & 58.0 & 36.9 & 31.0 \\
\hline \multicolumn{5}{|c|}{$\mathrm{a} 1 \mathrm{db}=$ Fundamental } \\
\hline \multicolumn{5}{|c|}{$\mathrm{a} 2 \mathrm{db}=$ Overtone 1} \\
\hline \multicolumn{5}{|c|}{$\mathrm{a} 3 \mathrm{db}=$ Overtone 2} \\
\hline
\end{tabular}

Table 6

\section{Cardinal vowels - 1760}

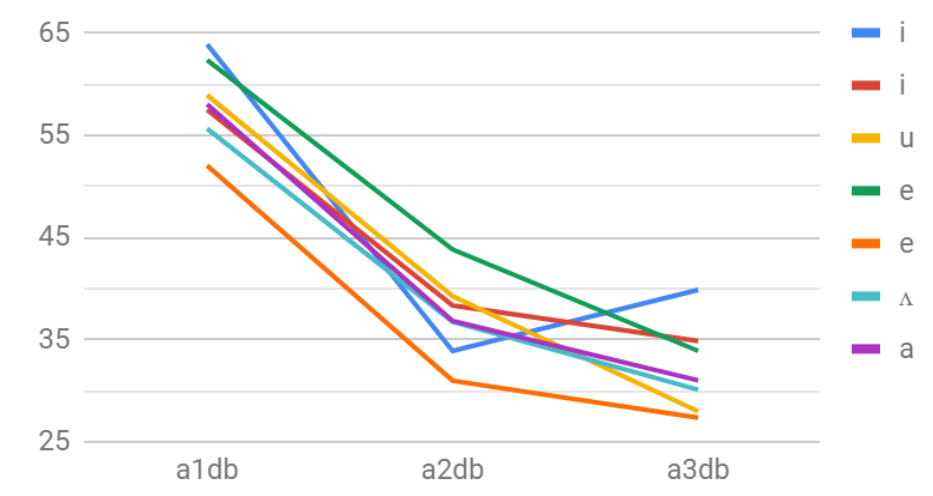

Graph 5. Cardinal vowels $-1760 \mathrm{~Hz}$. Values in decibels of fundamental, 1st overtone and 2nd overtone 


\begin{tabular}{|c|c|c|c|c|}
\hline $\begin{array}{l}\text { Table } 7 \\
\text { A } 1760 \mathrm{H}\end{array}$ & - Decibel va & damer & tone, a & one of front vowels \\
\hline Filename & Segment & $a 1 d b$ & $a 2 d b$ & $a 3 d b$ \\
\hline 8va_3 & i_la_1760 & 63.9 & 33.9 & 39.9 \\
\hline 8va_3 & i_la_1760 & 57.5 & 38.4 & 34.9 \\
\hline 8va_3 & I_la_1760 & 55.7 & 34.5 & 24.2 \\
\hline 8va_3 & e_la_1760 & 62.3 & 43.8 & 33.9 \\
\hline 8va_3 & e_la_1760 & 52.0 & 31.0 & 27.4 \\
\hline 8va_3 & E_la_1760 & 53.3 & 36.1 & 34.4 \\
\hline 8va_3 & æ_la_1760 & 57.8 & 42.0 & 39.6 \\
\hline $\mathrm{a} 1 \mathrm{db}=\mathrm{Fc}$ & ndamental & & & \\
\hline $\mathrm{a} 2 \mathrm{db}=0$ & ertone 1 & & & \\
\hline$a 3 d b=0$ & ertone 2 & & & \\
\hline
\end{tabular}

Table 7

\section{Front vowels $-1760 \mathrm{~Hz}$}

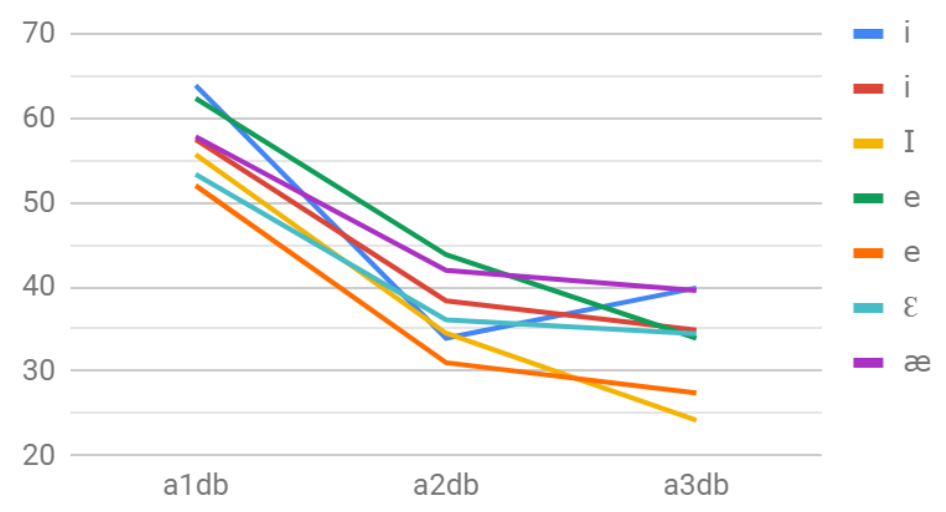

Graph 6. Front vowels $-1760 \mathrm{~Hz}$. Values in decibels of fundamental, 1 st overtone, and 2nd overtone. 


\subsubsection{Overall loudness}

This section evaluates each note in decibels. Every pitch has its chart and graph. The table has seven columns: the first column shows the used vowels, followed by the solfège syllables and Hertz; the second column lines up the ranking of vowels, [i] and [u] being the highest and [a] and [æ] the lowest. The third column has the overall loudness of every vowel; it is the outcome of combining all overtones of the note in that vowel. This column of the graph illustrates overall loudness; the Y-axis shows intensity and the X-axis shows vowel intensity, as in column two of the chart.

The fourth column displays the difference between the fundamental and the first overtone, column five does the same but taking the distance between the first overtone and the second overtone. It is visually appreciable in the previous spectrum graphs, however, there is exact distance between them. Finally, column six measures the energy at the beginning of the note. Column seven does the same but at the end of it.

\subsubsection{Fundamental - A 440Hz}

In $440 \mathrm{~Hz}$, Table 8 and Graph 7 show that the lower vowels are louder than the high vowels, which could be argued. However, [e] (high vowel) is in both extremes (loud and quiet) which removes any support to the previous evidence. Intensity at the beginning and the end of the note seems to have random values, not corresponding to vowel height or backness. 
Table 8

A - 440Hz Overall intensity index, distance between overtones, energy onset and end of the note.

\begin{tabular}{|l|l|l|l|l|l|l|}
\hline Segment & Height & SumA1To3 & A2-A1 & A2-A3 & AmpRise & AmpFall \\
\hline i_la_440 & 5 & 163.3 & 5.8 & 12.8 & 5.7 & -1.0 \\
\hline i_la_440 & 5 & 161.7 & 13.6 & 1.2 & -5.7 & -1.8 \\
\hline u_la_440 & 5 & 165.4 & 12.4 & 2.5 & 2.2 & -2.0 \\
\hline I_la_440 & 4 & 166.8 & 11.2 & 1.2 & 2.6 & -1.8 \\
\hline e_la_440 & 3 & 161.5 & 10.5 & 1.2 & 5.4 & -0.4 \\
\hline e_la_440 & 3 & 180.3 & 11.0 & 2.8 & -0.9 & 1.4 \\
\hline ^_la_440 & 2 & 163.1 & 13.7 & 5.0 & 8.9 & -5.1 \\
\hline E_la_440 & 2 & 174.1 & 12.5 & 1.9 & -3.7 & -3.2 \\
\hline a_la_440 & 1 & 174.8 & 12.0 & 2.0 & -1.8 & -2.6 \\
\hline æ_la_440 & 1 & 180.8 & 8.8 & 3.5 & -2.5 & -0.9 \\
\hline
\end{tabular}

SumA1to3 $=$ Overall intensity index.

A2 - A1 = Distance between fundamental and 1st overtone.

A2 - A3 = Distance between 1st overtone and 2nd overtone.

AmpRise= Energy at the beginning of the note.

AmpFall= Energy at the end of the note.

Table 8

\section{SumA1To3 vs. Height}

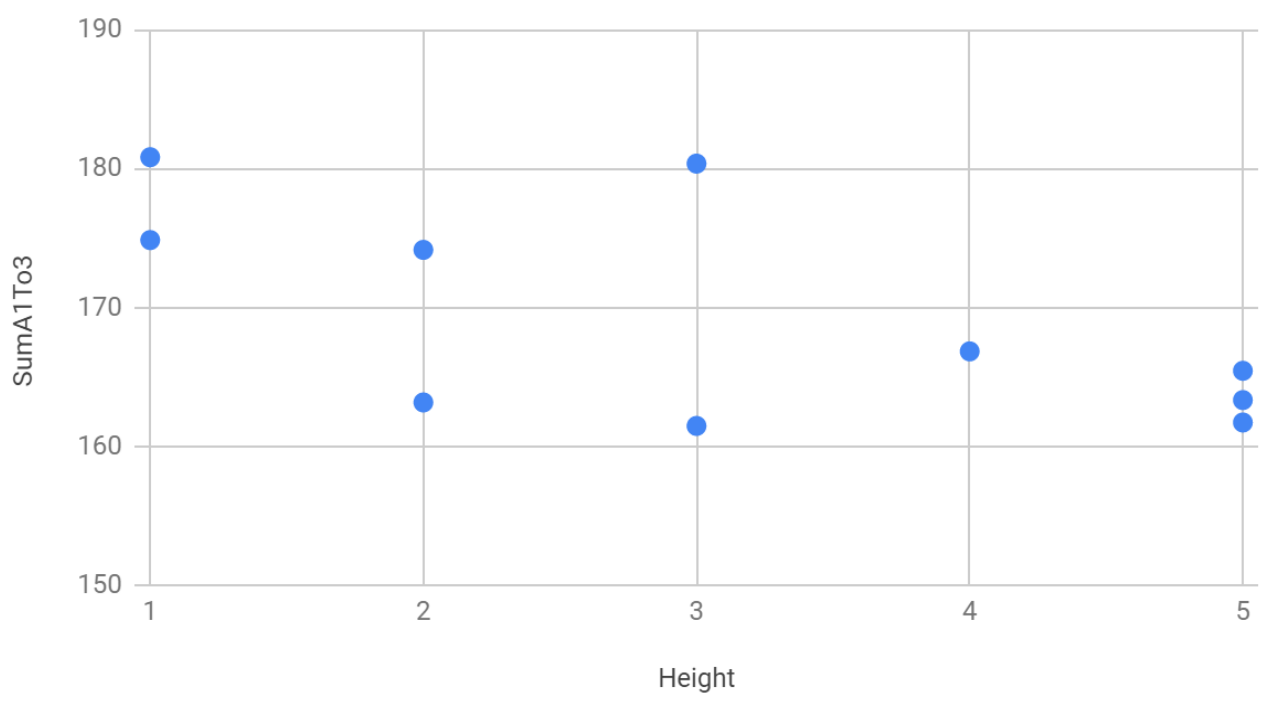

Graph 7. $440 \mathrm{~Hz}$ Index of overall intensity. X-Axis decibels; Y-Axis vowel height. 


\subsubsection{Fundamental - A $880 \mathrm{~Hz}$}

In $880 \mathrm{~Hz}$, Table 9 and Graph 8 shows that the two tokens of the high vowel [i] cover the whole range of overall intensity of the other vowels; it is the loudest and quietest. It is hard to see any correlation. As in the previous pitch, the intensity at the beginning and at the end of the note seems to have random values, not corresponding to vowel height or backness.

\begin{tabular}{|c|c|c|c|c|c|c|}
\hline \multicolumn{7}{|c|}{$\begin{array}{l}\text { Table } 9 \\
A-880 \mathrm{~Hz} \text { Overall intensity index, distance between overtones, energy onset and end of the note }\end{array}$} \\
\hline Segment & Height & SumA1To3 & A2-A1 & A2-A3 & AmpRise & AmpFall \\
\hline i_la_880 & 5 & 169.3 & 18.8 & 5.0 & -5.6 & -3.8 \\
\hline i_la_880 & 5 & 146.0 & 27.8 & 0.6 & -22.2 & 3.5 \\
\hline u_la_880 & 5 & 154.5 & 21.6 & 10.0 & 4.2 & 1.3 \\
\hline I_la_880 & 4 & 162.3 & 23.9 & 2.6 & 3.3 & 0.0 \\
\hline e_la_880 & 3 & 151.5 & 23.3 & 8.2 & 6.4 & 0.8 \\
\hline e_la_880 & 3 & 149.0 & 24.8 & 4.0 & 11.0 & 0.2 \\
\hline ^_la_880 & 2 & 158.7 & 18.5 & 8.2 & -12 & 2.9 \\
\hline E_la_880 & 2 & 161.7 & 22.3 & 3.0 & 0.6 & 5.7 \\
\hline a_la_880 & 1 & 159.6 & 19.4 & 7.2 & -8.6 & -10.6 \\
\hline æ_la_880 & 1 & 155.2 & 25.2 & 2.6 & 5.8 & -3.3 \\
\hline \multicolumn{7}{|c|}{ SumA1to3 = Overall intensity index. } \\
\hline \multicolumn{7}{|c|}{ A2 - A1 = Distance between fundamental and 1st overtone. } \\
\hline \multicolumn{7}{|c|}{ A2 - A3 = Distance between 1st overtone and 2nd overtone. } \\
\hline \multicolumn{7}{|c|}{ AmpRise= Energy at the beginning of the note. } \\
\hline \multicolumn{7}{|c|}{ AmpFall= Energy at the end of the note. } \\
\hline
\end{tabular}




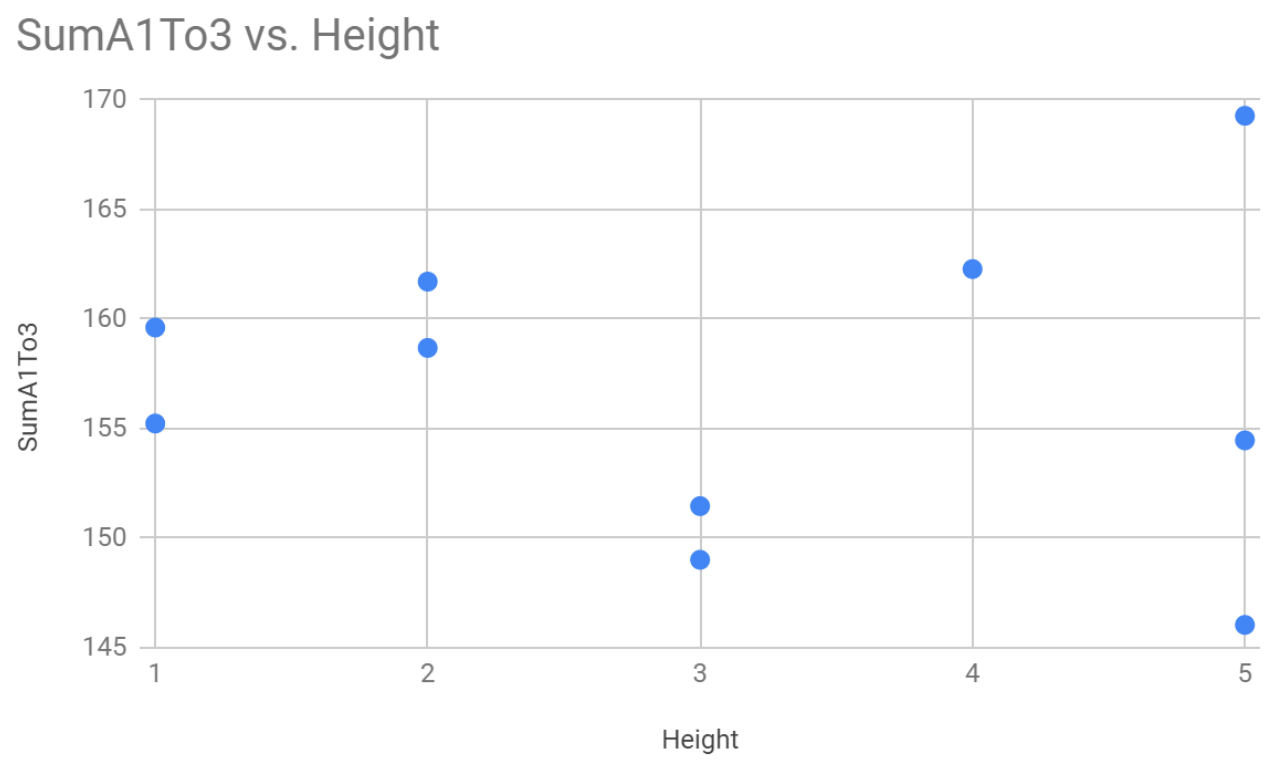

Graph 8. Overall loudness $880 \mathrm{~Hz}$. X-Axis decibels; Y-Axis vowel height.

\subsubsection{Fundamental - A $1760 \mathrm{~Hz}$}

This octave seems even more random than the previous results; there is no evident pattern. In Table 10 and Graph 9, the same intensity is seen in tokens of high, mid, and low vowels. 


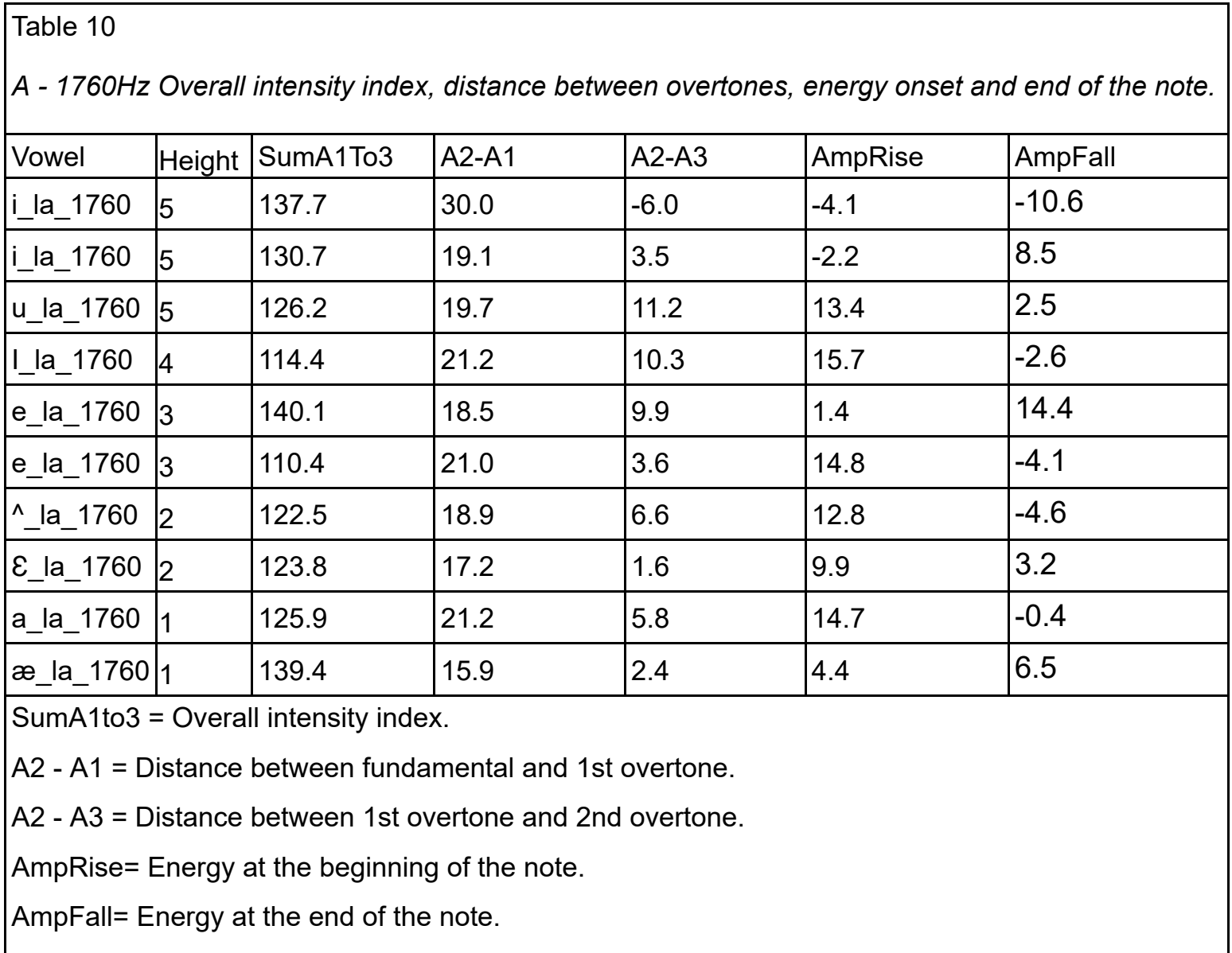

\section{Table 10}

\section{SumA1To3 vs. Height}

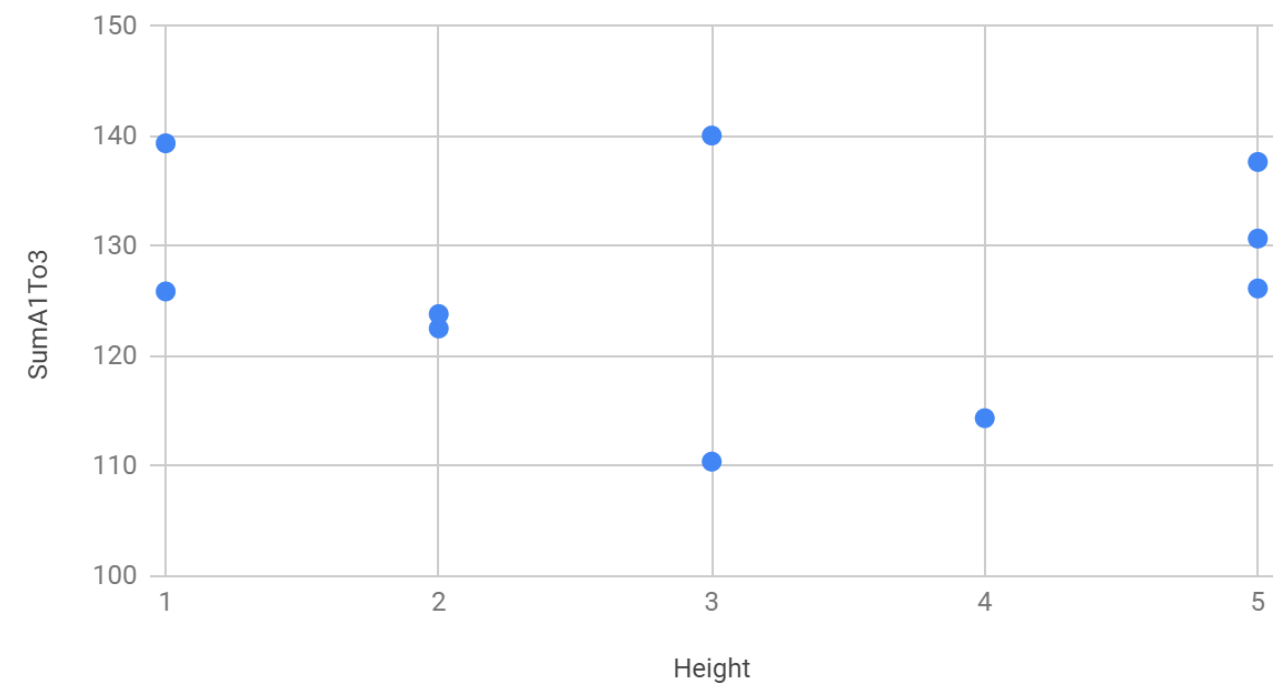

Graph 9. Overall loudness $1760 \mathrm{~Hz}$. X-Axis decibels; Y-Axis vowel height. 


\subsubsection{Combination of all vowels in all registers}

Graph 10 is the result of combining Graphs 7, 8, and 9. It gives a global perspective of overall loudness and appears to show a random pattern within a range. A possible argument would be that low vowels are louder. However, it does not have a strong fundamental. Even assuming that the previous claim is valid, the change would be minimal and hard to predict because it varies drastically in the same vowel.

\section{Energy in first 3 Harmonics}

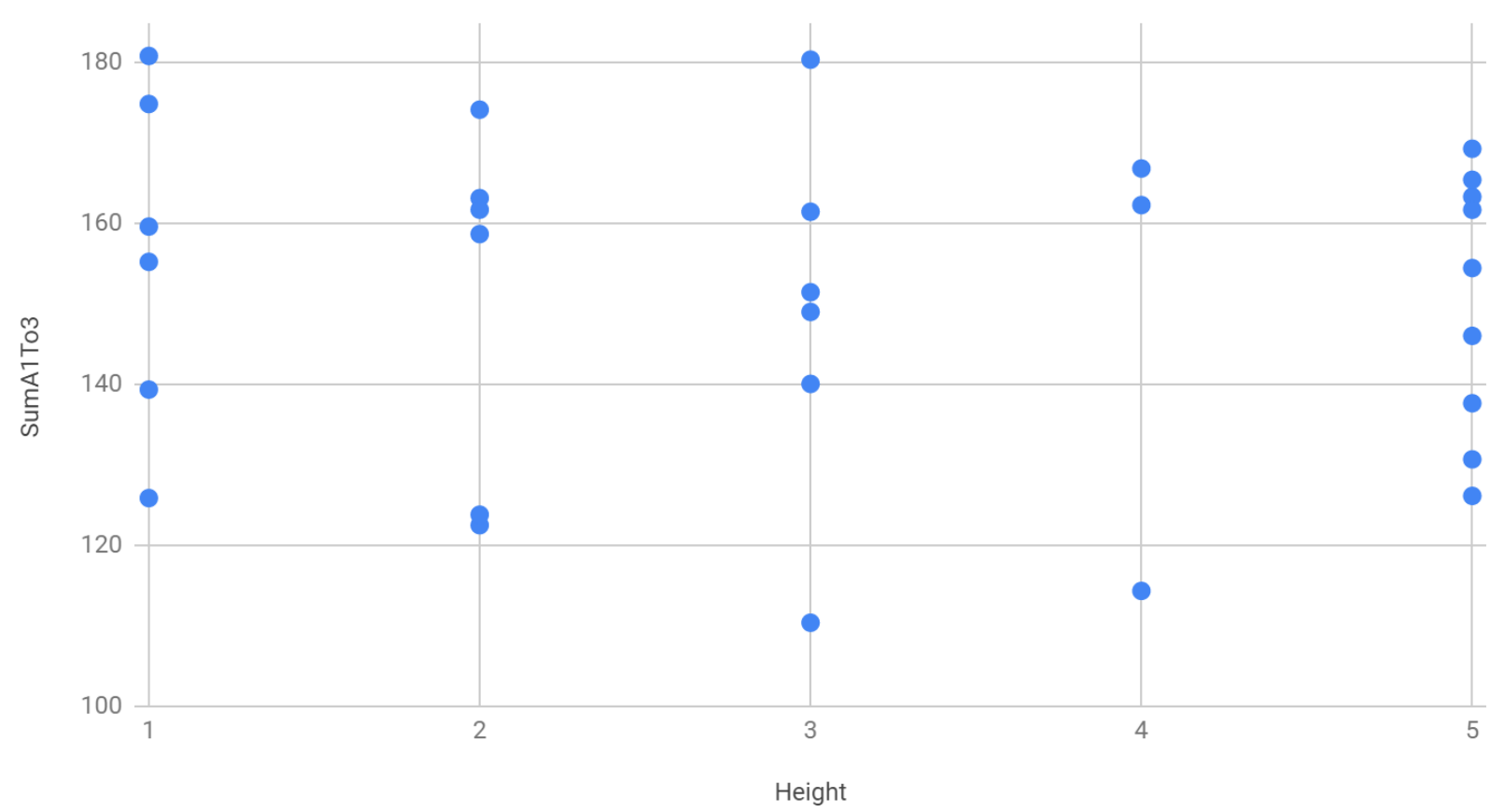

Graph 10. Overall loudness of all registers. X-Axis decibels; Y-Axis vowel height. 


\subsubsection{Specific spectral prominences}

The specific spectral prominences take two frequencies, A $880 \mathrm{~Hz}$ and A $1760 \mathrm{~Hz}$. Both have their chart and graph. Each spectrum is evaluated in two dimensions, as an overtone and as a fundamental. The lowest octave measured is $440 \mathrm{~Hz}$; its fundamental is $440 \mathrm{~Hz}$ and its overtone is $880 \mathrm{~Hz}$. The middle octave measured is $880 \mathrm{~Hz}$; its fundamental is $880 \mathrm{~Hz}$. These two octaves are compared through $880 \mathrm{~Hz}$ as an overtone and as a fundamental. The next octaves to be compared are the middle octave $880 \mathrm{~Hz}$ and the highest octave $1760 \mathrm{~Hz}$. These octaves are compared through the overtone and fundamental $1760 \mathrm{~Hz}$. If there is any change in a vowel, this comparison should show it. Phonetic vowels differ significantly, especially in their second formant (first overtone). So, it is expected that the vowel shape would show different results modifying flute sound.

In Tables 11 and 12, the first column specifies the rank in height followed by the vowel; the second column shows the used vowel, followed by the solfège syllable; the third column presents the energy (in decibels) of the note as an overtone; and the fourth column shows the energy of the note as a fundamental. All measurements are taken at the onset of the note. Graphs 11 and 12 represent the first overtone and the fundamental in decibels on the X-axis; on the Y-axis the value in decibels are measured. Notice that the values in the fundamental are higher than the values of $440 \mathrm{~Hz}$ overtone. This phenomenon is common in voice and every instrument. 


\subsubsection{1 $\underline{800 \mathrm{~Hz} \text { Specific spectral prominences }}$}

In $880 \mathrm{~Hz}$, the overtone of $440 \mathrm{~Hz}$ covers a range of 8.7 decibels, which is shown in Table 11 and Graph 11. The lowest vowel [æ] has the highest value, which contains one token. In contrast, one of the highest vowels [i] has the lowest value but contains two tokens. The two tokens of [i] encompass all the possible results in a range of 7 decibels in the first overtone at $440 \mathrm{~Hz}$, whereas the single token of [æ] is outside of this range by 2 decibels. [e] covers a range of 6.7 decibels, similar to the range of [i]. However, the distance of [e] is closer in proximity to the token of [æ] in 1.1 decibels. Overall, [i] and [e] are a major part of the possible results.

\begin{tabular}{|c|c|c|}
\hline $\begin{array}{l}\text { Table } \\
\text { A - 88C }\end{array}$ & Spec & prominences \\
\hline Vowel & $a 2 d b$ & $a 1 d b$ \\
\hline $5-i$ & 56.8 & 70.6 \\
\hline $5-i$ & 49.8 & 67.4 \\
\hline 5-u & 51.8 & 69.2 \\
\hline 4-I & 52.3 & 70.9 \\
\hline 3-e & 50.7 & 68.7 \\
\hline $3-e$ & 57.4 & 67.6 \\
\hline $2-\Lambda$ & 51.5 & 68.0 \\
\hline $2-\varepsilon$ & 54.5 & 69.7 \\
\hline 1-a & 55.0 & 68.5 \\
\hline 1-æ & 58.5 & 69.4 \\
\hline $\begin{array}{l}\mathrm{a} 2 \mathrm{db}= \\
\mathrm{a} 1 \mathrm{db}= \\
\text { Values } \\
\text { Measu }\end{array}$ & $\begin{array}{l}\text { it Over } \\
\text { undam } \\
\text { decibe } \\
\text { at the }\end{array}$ & of the note \\
\hline
\end{tabular}

Table 11 
a1db $(880 \mathrm{~Hz})$ vs. a2db $(440 \mathrm{~Hz})$

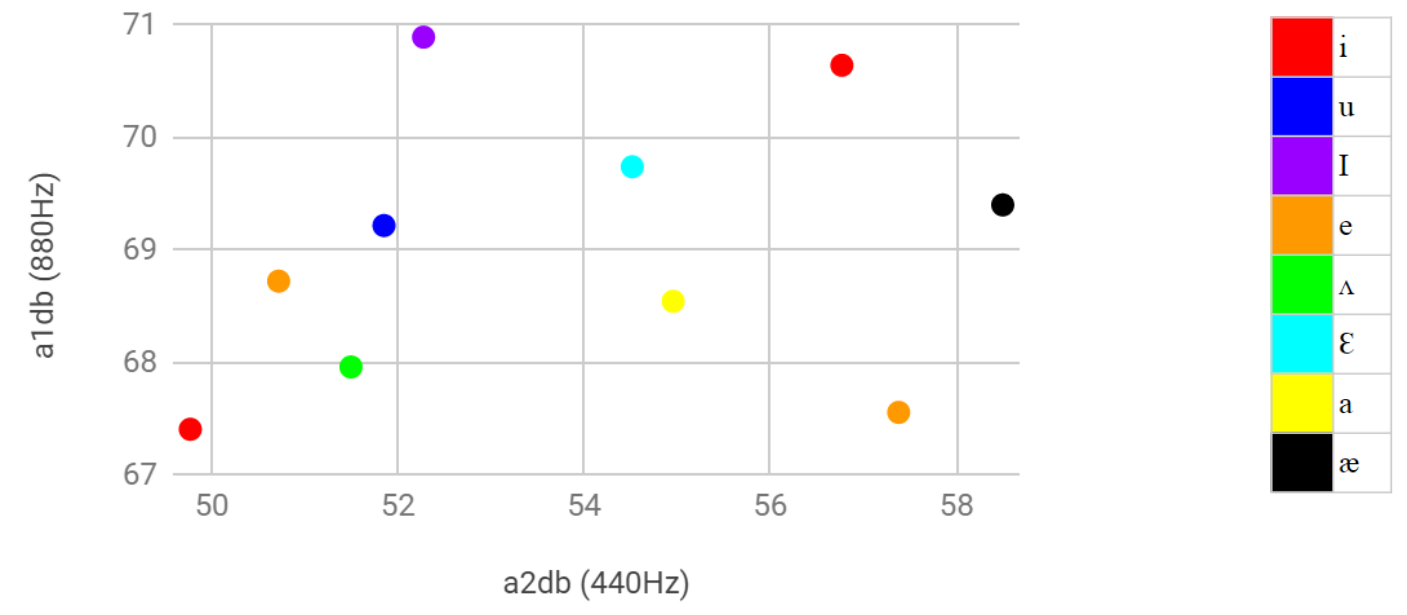

Graph 11 Value in decibels of $440 \mathrm{~Hz}$ first overtone and $880 \mathrm{~Hz}$ fundamental.

\subsubsection{2 $1760 \mathrm{~Hz}$ Specific spectral prominences}

In $1760 \mathrm{~Hz}$, the overtone of $880 \mathrm{~Hz}$ covers a range of 12.2 decibels. In Table 12 and Graph 12, the highest value is [i] and the lowest value is [i]. In the fundamental $1760 \mathrm{~Hz}$, the highest value is one of the tokens of [i] and the lowest value is one of the tokens of [e], which are in the same area in a vowel phonetic perspective. 


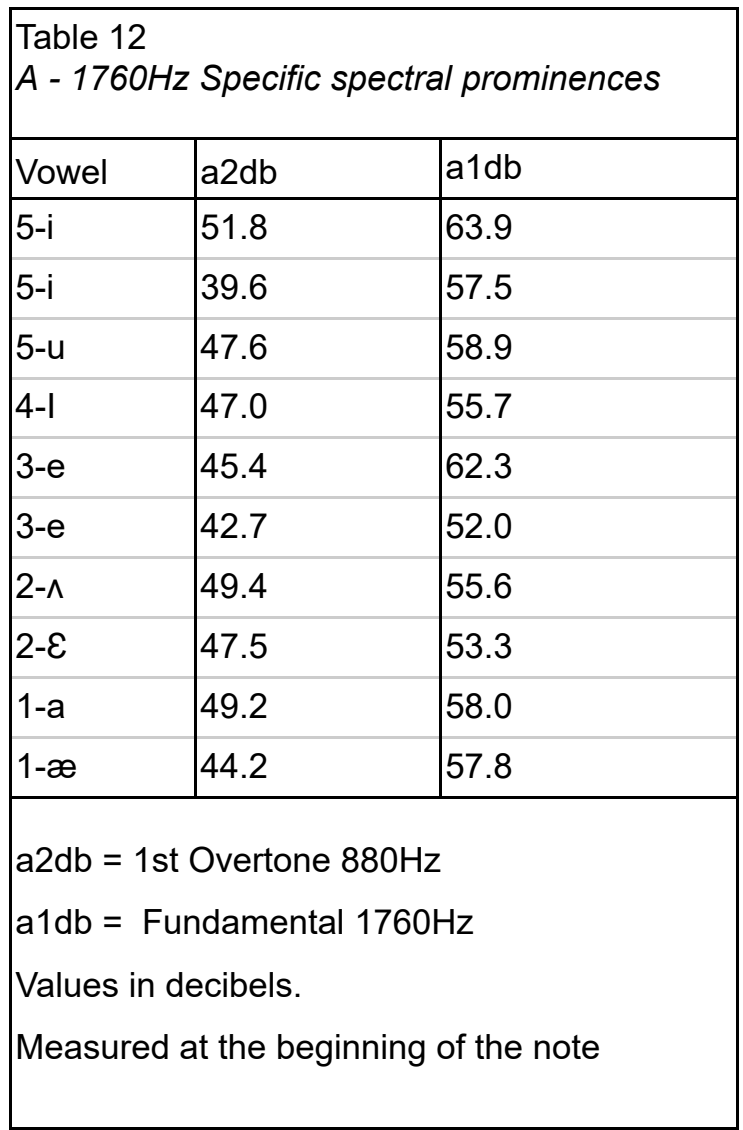

Table 12

a1db (1760) vs. a2db (880Hz)
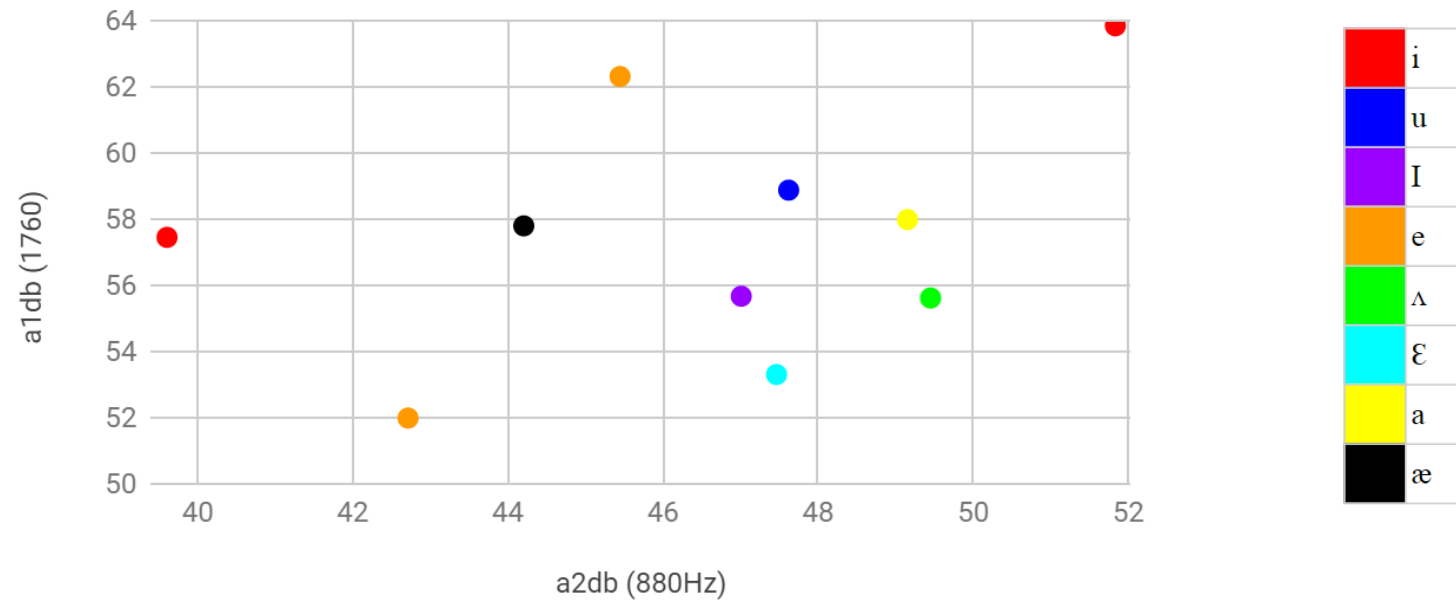

Graph 12. Value in decibels of $880 \mathrm{~Hz}$ first overtone and $1760 \mathrm{~Hz}$ fundamental. 


\section{CHAPTER III: DISCUSSION}

\subsection{Results: summary}

After collecting the results and analyzing them individually, the measurements give us enough information to discuss in broad terms what happened in each part of the experiment and its analysis.

The main concern of this thesis is to discover any correlation between vowel shapes and flute sound. First, we consider the first three partials of the spectral analysis. All notes have the same form except two. The first different note is one token of [i] in the first octave of the flute. It still follows the same pattern, the fundamental being higher than the second one and the third one being lower. The second note is one token of [i] in the third octave, its second overtone is higher than the others, but it is 0.3 decibels away to [æ] (low vowel) which is contradictory if there were a vowel correlation.

Additionally, the difference is minimal, and the two tokens of the same vowel show the difference in those minimal changes. The results in this part of the experiment seem to support the claim that vowel shapes affect flute sound. If the argument were correct, each form would look different. Due to its spectral properties, it is expected that vowels having a high energy component in two notes would have the same quality, but the data shows different results.

In overall loudness, it seems that low vowels tend to sound louder in the first octave. Nevertheless, one token of [e] (high mid front vowel) is almost at the same level than the loudest pitch. The difference between [e] and [æ] is 0.5 decibels. Furthermore, one token of [e] is the 
loudest, and the other token of [e] is the quietest with a range of 18.8 decibels. In the second octave, one token of [i] is the loudest and the softest, covering a range of 23.3 decibels. It is difficult to see any pattern, including the third octave and the combination of all notes. It seems that the data is forming random patterns inside a range of loudness, which is not directly connected with vowel quality.

The specific spectral prominences are a comparison between the same frequency as a fundamental and as an overtone. It presents some correlation between the two data sets, as the values share spectral properties. However, no evidence corresponds with the already known vowels. In the results, it is shown that the tokens of [i] cover a considerable portion of the possible outcomes of the other vowels, suggesting no systematicity. Nevertheless, some of the loudest components are high vowels.

In the tests, $[\mathrm{u}]$ does not show any notable difference from any other vowels. It is not at the extreme high or low end of the observed values. The results fail to demonstrate that vowel height make a significant difference. The front-back dimension, as the tongue body advances forward and the corona approximates the hard palate, also fails to demonstrate any notable change. $[u]$ it is both back and rounded, and in contrast to most of the other vowels does not seem to have any systematic effect on loudness, spectral slope, or the strength of partials at any particular frequency.

Additionally, a statistical measurement was used to determine correlation. It determines if the values in the first variable (first overtone) are explained in the second variable (fundamental). 


\subsubsection{Measure correlation between series:}

The Pearson Product-Moment Correlation Coefficient (PPMCC) was used to measure the strength of the linear relationship between the two variables. It gives a value on how closely related the two variables are.

The PPMCC is expected to give values between +1 and $-1 .+1$ indicates total positive linear correlation, 0 is no linear correlation, and -1 suggests a negative linear correlation.

Variables

440Hz Overtone $1880 \mathrm{~Hz}$ Fundamental

Pearson's value for $880 \mathrm{~Hz}=0.24$

Variables

$880 \mathrm{~Hz}$ Overtone $1 \quad 1760 \mathrm{~Hz}$ Fundamental

Pearson's value for $1760 \mathrm{~Hz}=0.35$

\begin{tabular}{|l|l|}
\hline$\%$ VarianceExplained & 0.12 \\
\hline
\end{tabular}

The statistical results show that there is a certain amount of variability in the values ranging from $6 \%-12 \%$. The rest is variability that we do not know, $88 \%-94 \%$. The percentage of variance is small, random, and not explained by the Theory of Vowels.

There are two levels in which the correlation results raise interesting questions. First, it needs to be determined whether a vowel articulation that reinforces a particular frequency on one occasion also tends to reinforce that frequency on other occasions. In the collected data, there is a small and variable tendency for correlation. The second question raised is whether the frequencies that different vowels appear to reinforce bear any systematic relationship to their 
physical/acoustic properties, which does not seems to be true. It is not the case, for instance, that low vowels with $\mathrm{F} 1$ values near $880 \mathrm{~Hz}$ reinforce that frequency more than high vowels with $\mathrm{F} 1$ values far away from $880 \mathrm{~Hz}$. Even if we accept that the tendency of particular vowel articulations to reinforce certain frequencies is 'real', the relationship must be governed by something other than the specific resonant frequencies of the vowels in question. According to the results, it is difficult to say what that relationship would be.

\subsection{Conclusion}

The evidence in this thesis fails to find a pattern of preliminary influences of vowel articulation on flute sound. The theory of vowels and acoustics more generally suggest that claims concerning vowel quality and flute timbre may not be correct; empirically, this exploratory study failed to find any systematic or obvious effects of vowel features on the acoustics of flute sounds. There is no gross difference in vowels; all shapes are overall the same, and there are no significant differences in loudness of different vowels. In conclusion, there is not a consistent pattern between back/round or front/unrounded vowels. If there is any change in high and low vowels, it would be minimal, and any consistent output would be complicated to obtain. The difference that we are considering is in decibels (loudness), not any change in timbre (color). That change in loudness could be obtained by playing with high volume without considering any vowel. Strictly judging from the results measured in this experiment, there was no detectable pattern in vowel articulations resonating with flute sound.

The topic of vowel shape could have a story similar to the myth of the diaphragm supporting the air column in singers and wind instruments. Both are topics that go beyond the 
musicians' knowledge, and there could be misunderstandings. However, a flutist does not necessarily know about vowel acoustics or the physic-acoustics of the instrument. On the other hand, an expert flutist is not necessarily an expert physician, and their knowledge regarding the anatomy of the diaphragm could be limited. When two branches of knowledge meet, they can solve misunderstandings and clarify myths. Presently, we know that the saying "use your diaphragm to support the pitch" (Alt 1990) it is not true, and took decades to comprehend. The efforts to improve the field and discover what is behind the myth comes from curiosity and questioning the patterns that have already been established. This thesis strives to encourage interdisciplinary studies challenging those pattern and exploring other perspectives. Here, the field of linguistics is clarifying that it is unlikely to change the color of the flute by shaping vowels in the mouth.

Because singing is one of the first expressions of music, flutists often try to imitate singing while playing. There are multiple teachings that reinforce the concept that singing and playing the flute are similar, such as support of air flow, vibrato, expression, connecting and shaping phrasing. Those concepts are supported by qualified musicians, which leads to widespread belief that singing and flute playing are closely related. Professional musicians are often motivated to explore all possible sounds and techniques of an instrument. By doing this, musicians create different ideas to modify sound and expand an instrument's possibilities. Through this exploration, false ideas could spread and are considered facts even though they have not been proven. Overall, these issues contributed to the false belief that vowel articulations can modify the timbre of a flute according to the data collected in this experiment. However, if a 
wider range of data were gathered in this experiment, different patterns could be detected, which would cause overall conclusions to change.

\subsection{Pedagogical implications}

There is literature and commentary from different flutists supporting a theory where vowel shapes make music more interesting; some instructors suggest practicing vowels to expand the possible interpretative skills of the students. Based on the results of this study, there is no substantial evidence to support that claim. Instead, students should concentrate their time and energy on overcoming other difficulties on the flute. If there is any vowel preference, that decision will come from a subjective basis of the performer, for instance giving a comfortable feeling playing, sounding better to the flutist, or matching with that particular instrument. Those claims would change depending on individual perception, not scientific fact. Additionally, there could be a claim stating that a minimal change would affect the music. However, from the data that we have, that minimal difference is difficult to predict. If there is a concrete recommendation for flutists, it would be to allow the air to go through and reduce any unnecessary resistance in the jetstream of air.

\subsection{Pilot perception study}

In spring 2018, the author, an experienced flutist with a graduate degree, conducted a pilot study. The goal of the study was to determine if participants can audibly distinguish between different vowels articulations in a flute. The author recorded the samples; no voicing of vowels or vibrato were used. The shape inside the mouth was the only differentiating factor when 
comparing the recordings. The cardinal vowels $[\mathrm{a}],[\mathrm{i}]$, and $[\mathrm{u}]$ were recorded in one pitch, $\mathrm{A}=$ $440 \mathrm{~Hz}$. Five musicians with nine to twenty years of experience in music and one without experience took the survey. Two of the musicians were flutists. The survey asked for their instrument, years of experience in music, and five tests of vowel distinction. Three of the tests asked to identify each cardinal vowel in isolation. The other two tests challenged the participants to identify the order of vowels articulations in series of three (eg. [i], [a], [u] and [a], [i], [u]). Although, participants could hear the recording as many times as they wanted, they answered correctly less than half of the time; of 25 total answers, only 5 were correct. For [i] there were no correct answers, for [u] $60 \%$ of the answers were correct, and [a] $20 \%$ of the answers were correct. In the series of three vowel articulations [i], [a], [u] there were $20 \%$ correct answers and in the series of [a], [i], [u] there were no correct answers. Results and questions can be found in the appendix.

\subsection{Future studies}

A subsequent researcher can replicate this work of analysis and perception using more data from different flutists, preferably performers who believe vowel shapes change the timbre of the instrument. In this acoustic analysis, one experienced flutist was recorded and in the pilot perceptual study, one flutist was recorded and five participants took the survey. The results in these two studies contradict other researchers' results as well as years of conventional knowledge of colleagues and famous flutists, and it would be valuable to perform these experiments on a larger scale despite the present evidence suggesting no correlation. In future auditory tests, it 
would be beneficial to create general questions that ask participants if they can detect any differences in sound production, which would be simpler than the hearing test in the pilot study.

The next step for this research is to investigate consonants in flute sounds. Future research would investigate how consonants in flute sound work physically, acoustically, and any implication in the relationship between consonants and vowels. Although every mouth is different and every flutist is a whole universe, a study of this kind would yield generalizations and suggestions.

Although this study failed to find a consistent pattern regarding vowel articulations, there are many variables that determine the individual characteristics of flute sound. In the future, it would be beneficial to explore which characteristics contribute to the unique production of sound in a flute. After identifying the major contributing factors, it would allow the specific variables that influence the sound variation to be measured and analyzed. 


\section{APPENDIX}

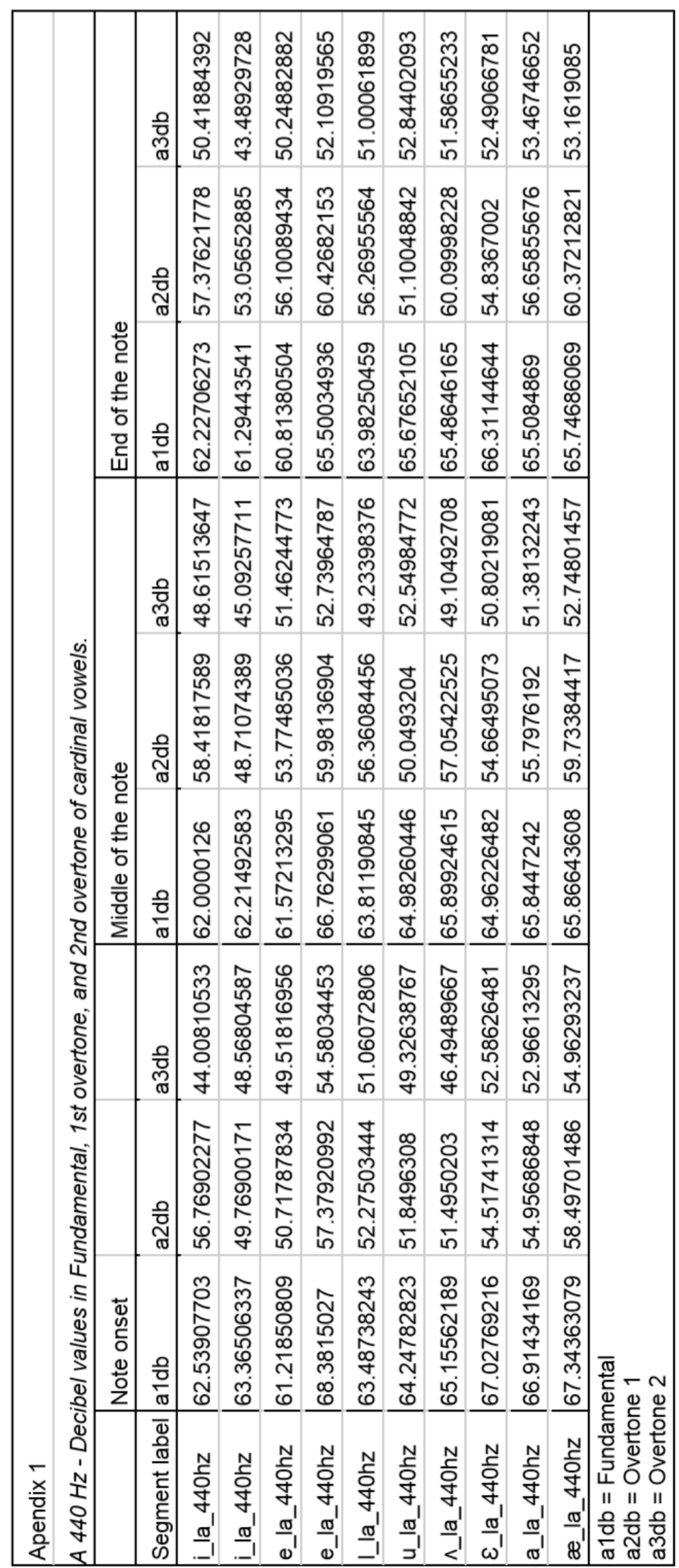




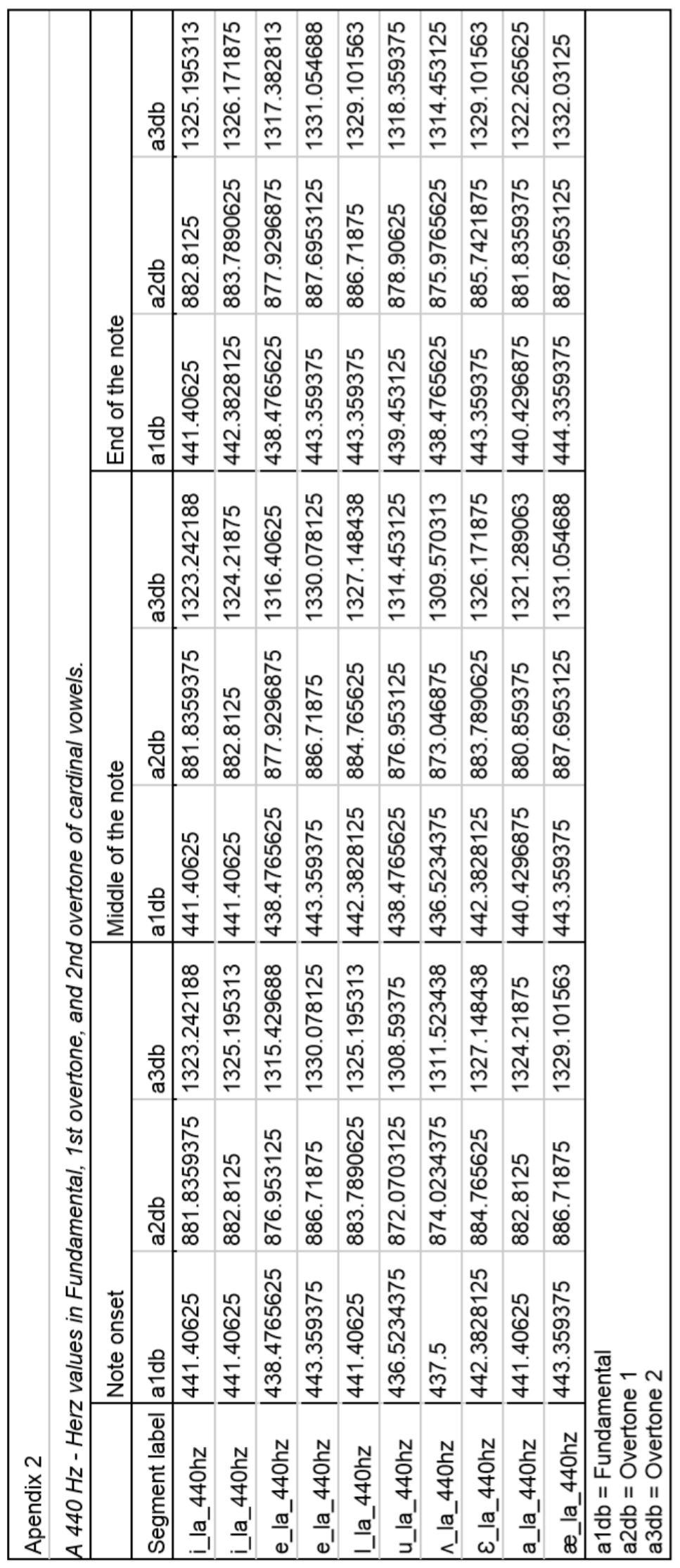




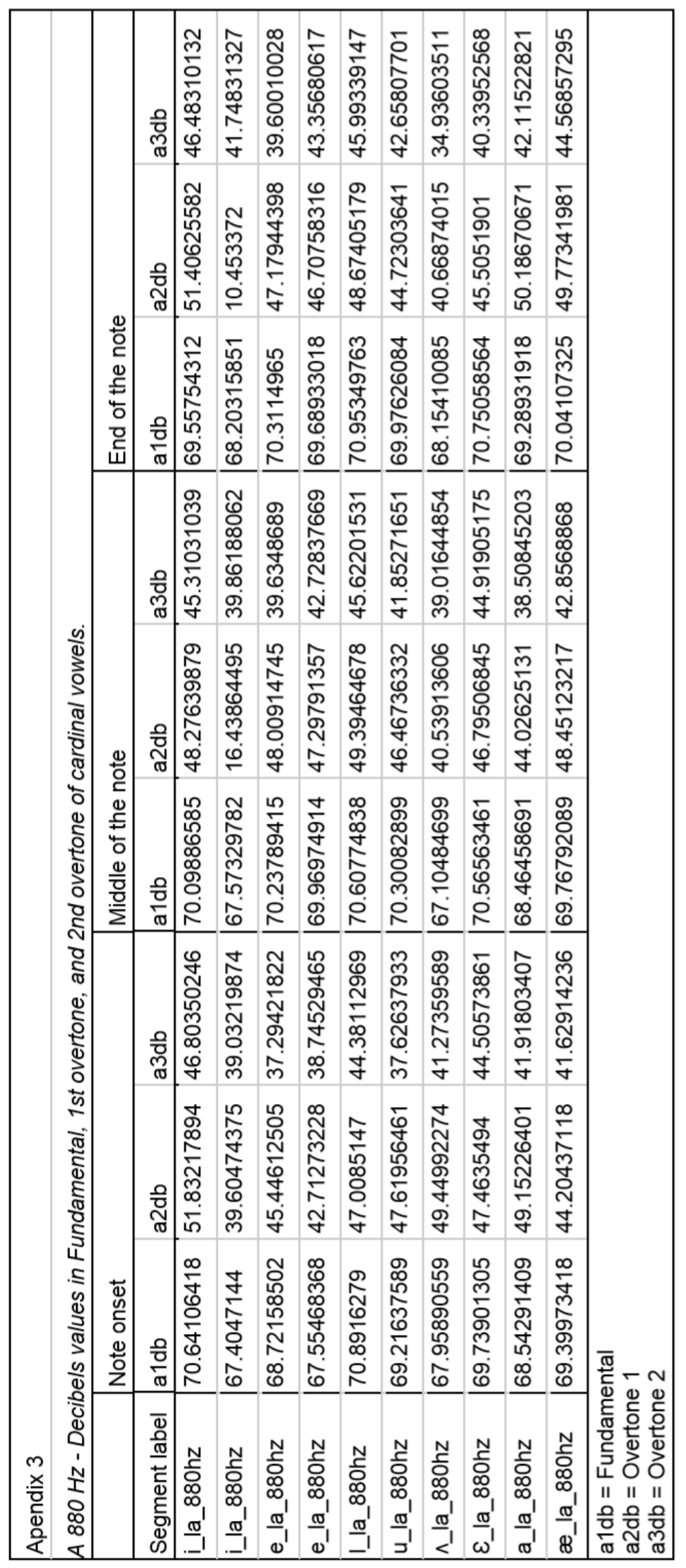




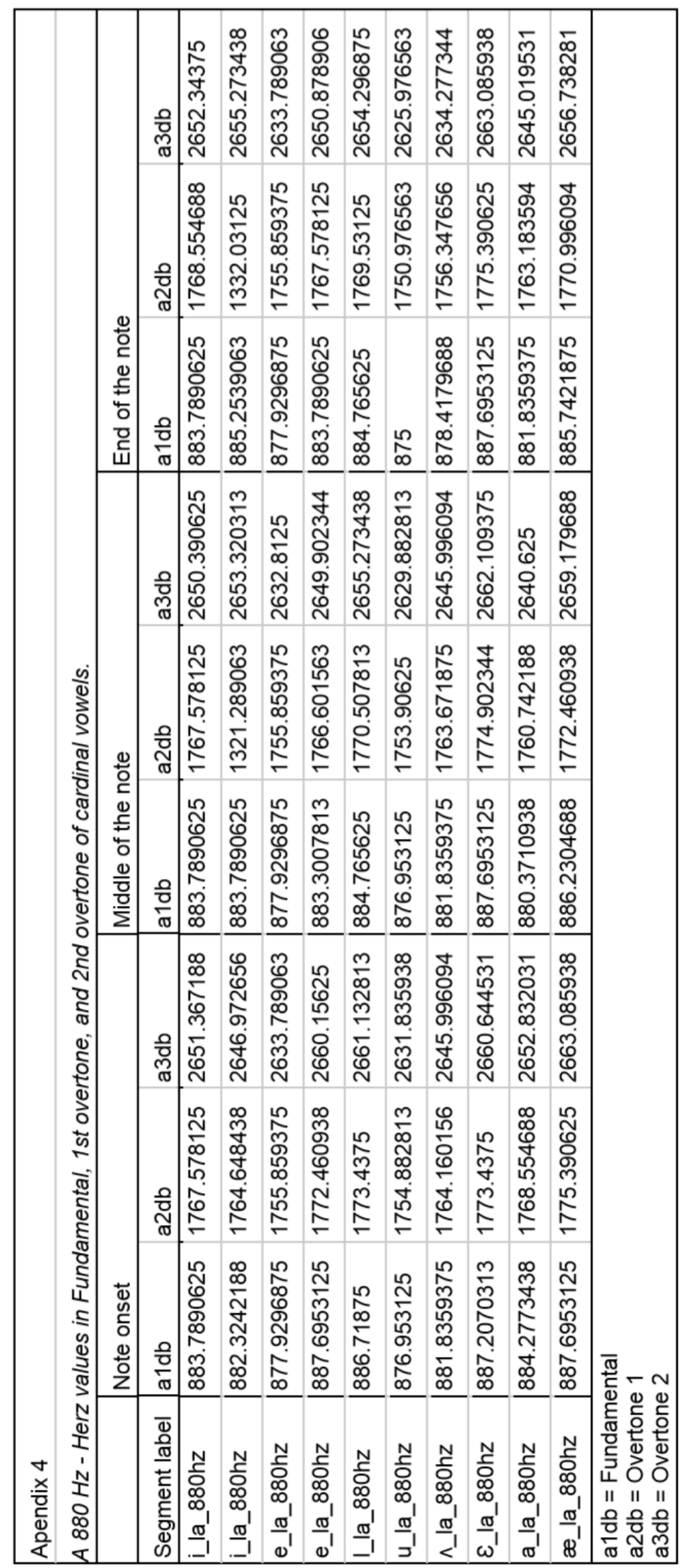




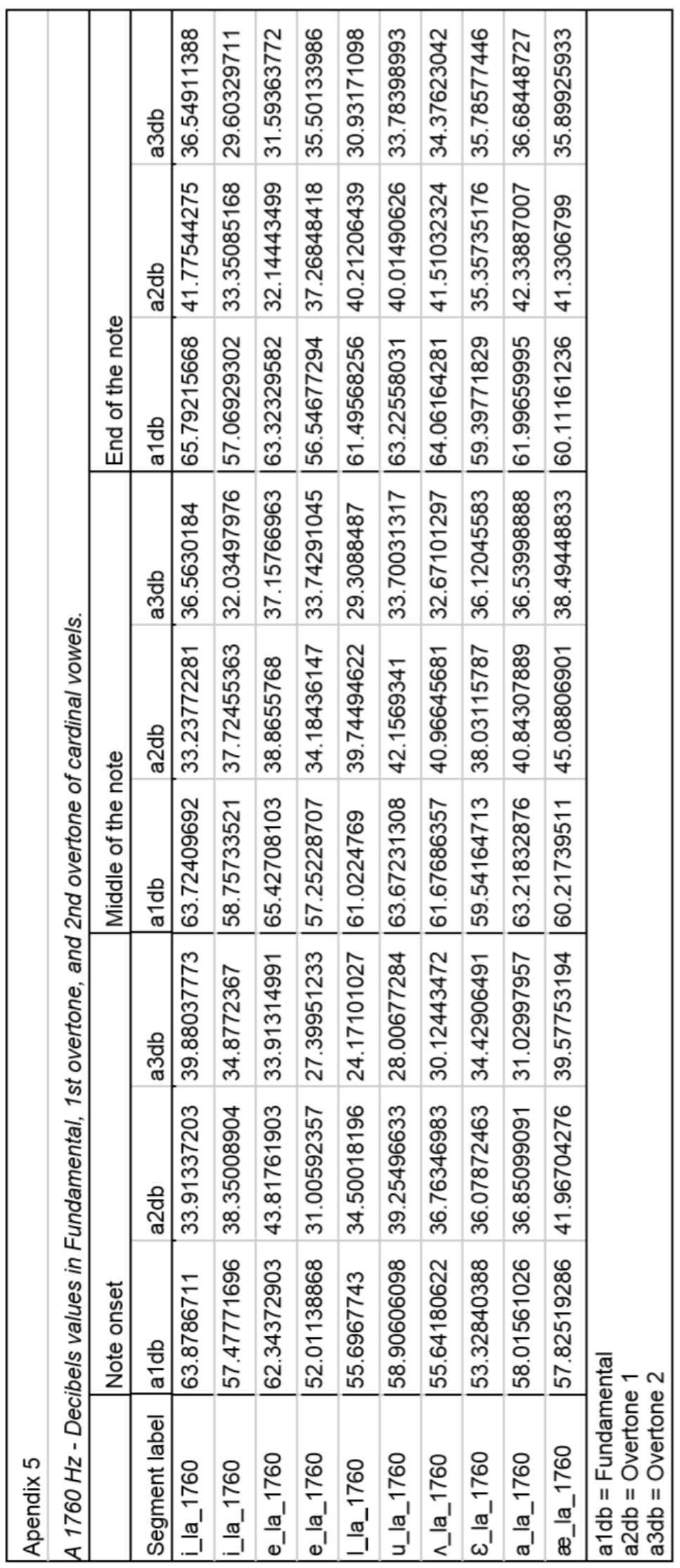




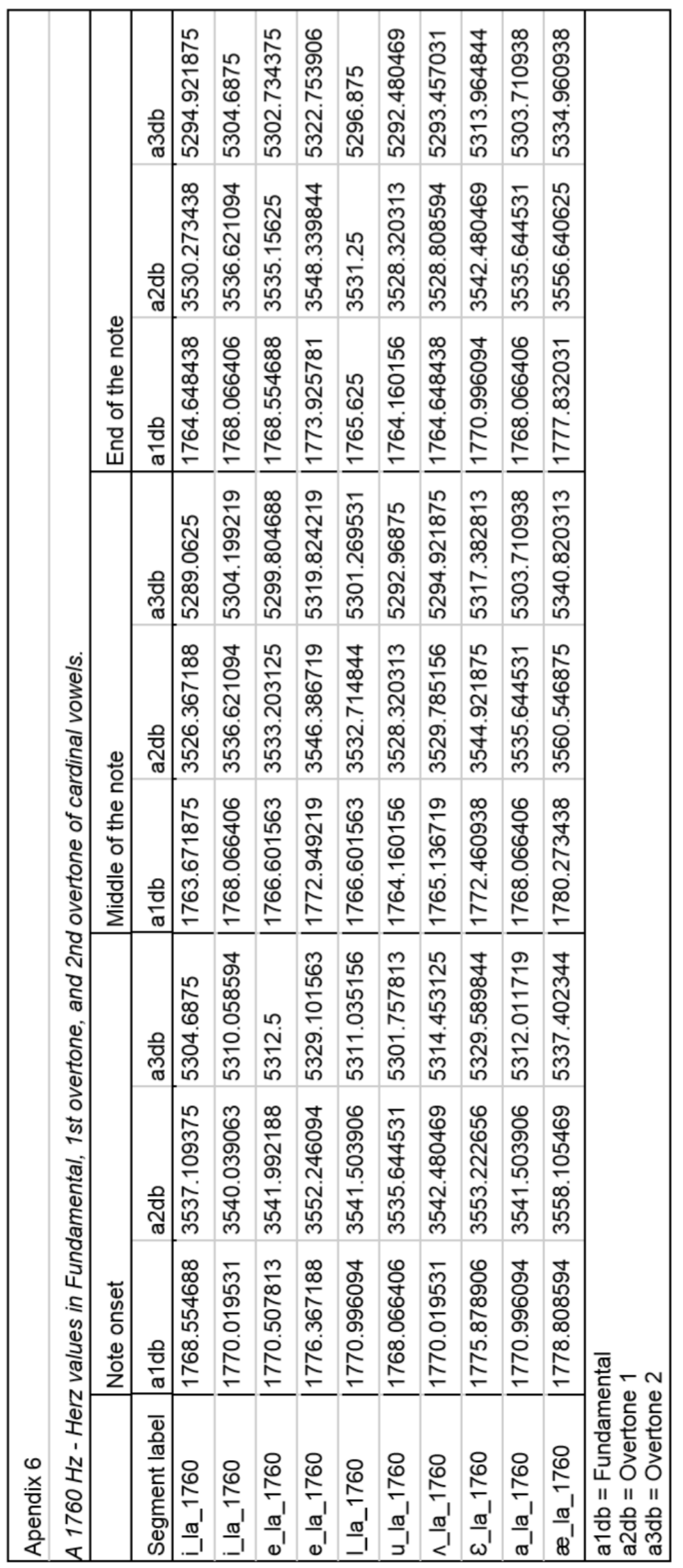


Pilot perception study

\section{Results:}

Are you a musician?

5 responses

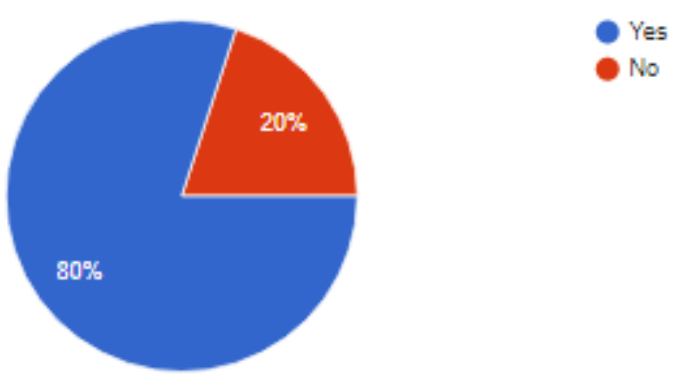

If yes, which instrument or instruments do you play?

4 responses

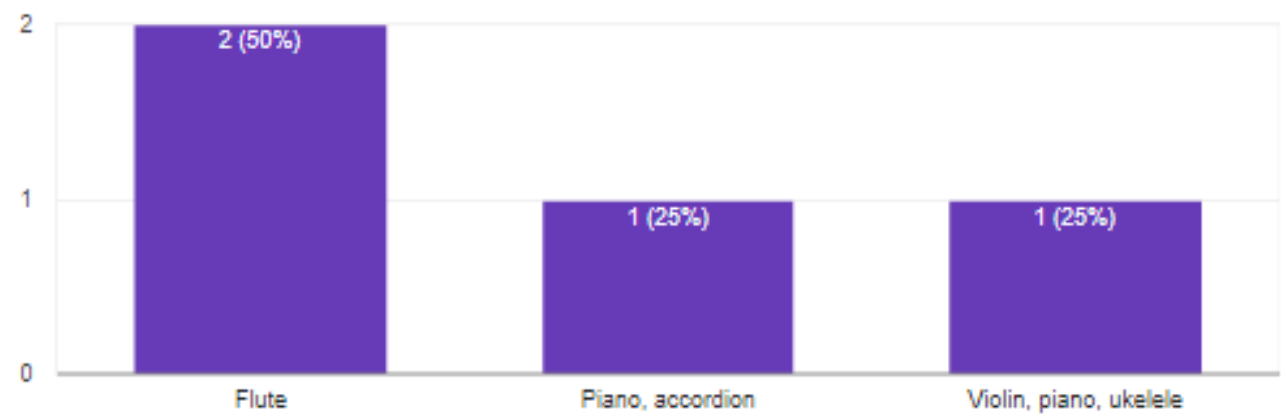


How long have you been playing your principal instrument?

4 responses

20 years
9 years
15 years
10 years

Correct answer: [i]

5 responses
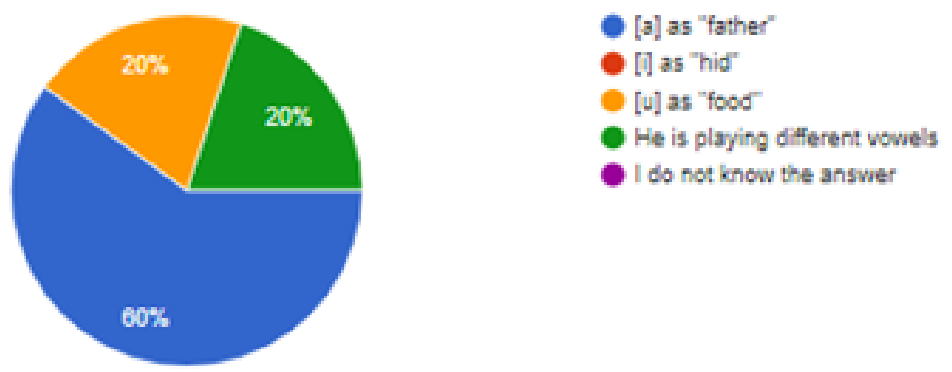

Correct answer: [u]

5 responses

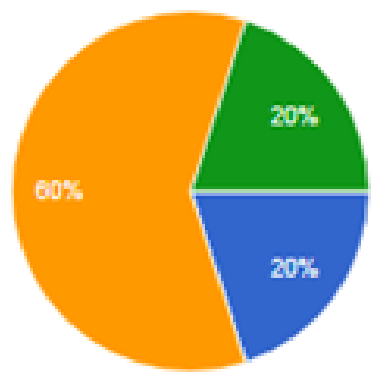
- [a] as 'facher'
- [1] as 7ild
[v] as "food"
- He is playing diffecent vovels
- I do not know the answer


Correct answer: [a]

5 responses

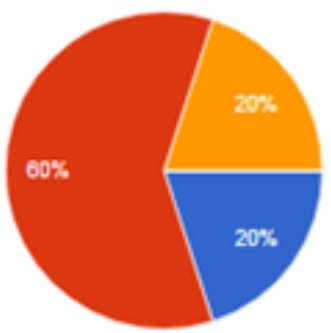

- [a] as "father'

- [1 as "his"

[U] as " 7000 "

- He is playing diffecent vowels

- I do not know the answer

Correct answer: [i] [a] [u].

5 responses

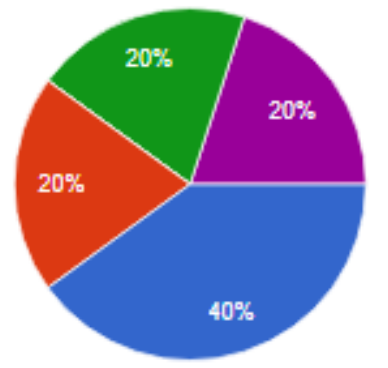

[a] [i] [u]

- [] [a] [u]

[1] [u] [a]

[u] [a] [a]

- I do not know the answer

\section{Correct answer: [a] [i] [u]}

5 responses

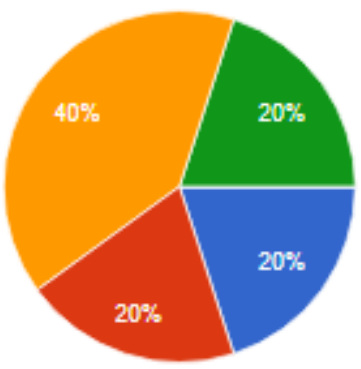

$[a][i][u]$
$[a][u]$
$[u[u][a]$
$[u][a][]$
I do not know the answer 


\section{REFERENCES}

Alt, David (1990). "Misunderstanding Breath "Support" for Singers." The Choral Journal 30, no. $8: 33-35$.

Boersma, Paul \& Weenink, David (2019). Praat: doing phonetics by computer [Computer program]. Version 6.0.49, retrieved 2 March 2019 from http://www.praat.org/

Carr, Walter E. (1978). A Videofluorographic Investigation of Tongue and Throat Positions in Playing Flute, Oboe, Clarinet, Bassoon, and Saxophone. Order No. DP29445, University of Southern California.

Cela, Orlando. "FluteLab - Vowels, Consonants, and Sound Production." YouTube, YouTube, 15 Dec. 2012, www.youtube.com/watch? $=$ =ANbl7jkSVlQ.

Clark, Michael J., Getty, Laura A., Hillenbrand, James \& Wheeler, Kimberlee (1995) Acoustic characteristics of American English vowels. Western Michigan University.

Johnson, K., Sherman, V. C., \& Sherman, S. G. (2011). Acoustic and auditory phonetics. Retrieved from https://ebookcentral.proquest.com

Ladefoged, Peter, and Johnson, Keith (2011). A Course in Phonetics. Wadsworth Cengage Learning.

Lehnert-LeHouillier, Heike (2007). The perception of vowel quantity: A cross-linguistic Investigation. Ph.D. diss., State University of New York at Buffalo.

Schlafer, Julie (2006). A Linguistic Analysis of the use of Vowels to Affect Voicing on the Bassoon. Order No. 3220778, Arizona State University.

Rigler, Jane A. (1996). Flute Vocalization: An Integrated Approach to Performance. Order No. 9940460, University of California, San Diego.

Roberts, Myles (2017). The life of Raffaele Trevisani, and his contribution to modern day flute pedagogy. MM. Thesis., Stellenbosch University.

Southworth, C. (2010). Colors and Sound. Miyazawa. Retrieved from http://www.miyazawa.com/media-library/educational-articles/technology/colors-and-soun d/ 
Schwartz, Alyssa M. (2018). Study of the resonance spectrums of the flute and the effect of different stable vowels on formant tuning with violin and clarinet. Ph.D. diss., West Virginia University.

Walker, Kerry E. (1995). Cheek Inflation and Vowel Posture Techniques for the Flutist:

The Exploration of a Kincaid Vision of Resonance made through Analogies to Vocal Pedagogy. Order No. 9610833 Texas Tech University.

Wilcocks, Gerda R. (2006). Improving tone production on the flute with regards to embouchure, lip flexibility, vibrato and tone color, as seen from a classical music perspective. Pretoria University. 